\title{
Epidemiology and molecular mechanisms of antifungal resistance in Candida and Aspergillus
}

\author{
Sarah Santos Gonçalves, ${ }^{1}$ Ana Carolina Remondi Souza, ${ }^{1}$ Anuradha Chowdhary, ${ }^{2}$ \\ Jacques F. Meis ${ }^{3,4}$ and Arnaldo Lopes Colombo ${ }^{1}$ \\ ${ }^{1}$ Laboratório Especial de Micologia, Disciplina de Infectologia, Escola Paulista de Medicina, Universidade Federal de São Paulo, São Paulo, SP, Brazil, \\ ${ }^{2}$ Department of Medical Mycology, Vallabhbhai Patel Chest Institute, University of Delhi, Delhi, India, ${ }^{3}$ Department of Medical Microbiology and Infectious \\ Diseases, Canisius Wilhelmina Hospital, Nijmegen, the Netherlands and ${ }^{4}$ Department of Medical Microbiology, Radboud University Medical Centre, \\ Nijmegen, the Netherlands
}

\section{Summary}

\begin{abstract}
The significant increase in the use of antifungal agents, both for the treatment of candidiasis and invasive aspergillosis and as azole fungicides in agricultural crop protection has resulted in the emergence of resistant clinical isolates, particularly to triazoles and echinocandins. Notably, among isolates that were primarily sensitive to fluconazole such as Candida parapsilosis and Candida tropicalis have witnessed an emerging resistance development. Also for echinocandins, the occurrence of Candida isolates with lower susceptibility to these drugs has been reported, which is possibly due to its broad clinical use. Triazole resistance among Aspergillus fumigatus and other Aspergillus species is commonly found in European and Asian countries. Specific mutations are associated with azole resistance in A. fumigatus and these mutations are now reported globally from six continents. Therefore, we highlight the need to conduct antifungal resistance surveillance studies using clinical isolates of Candida and Aspergillus in different geographical regions and monitoring of the infection rates in distinct population groups for early detection of resistance to these drugs and implementation of efficient policies for infection control and treatment.
\end{abstract}

Key words: Antifungal resistance, Candida spp., Aspergillus spp., azoles, echinocandins, amphotericin B.

\section{Introduction}

In recent decades, there has been a substantial increase in the occurrence of invasive fungal infections (IFIs) due to Candida and Aspergillus in tertiary hospitals throughout the world. ${ }^{1-3}$ Despite the large geographical variability in their incidence rates, IFIs have undoubtedly become very important worldwide, particularly among critically ill patients, those with degenerative or neoplastic diseases and in patients

Correspondence: Arnaldo Lopes Colombo, Laboratório Especial de Micologia, Universidade Federal de São Paulo, Rua Pedro de Toledo, 669 - $5^{\circ}$ andar, CEP 04039-032, São Paulo, SP, Brasil.

Tel.: +55 115576 4848. Fax: +55 1150813240 .

E-mail: arnaldolcolombo@gmail.com

Submitted for publication 25 October 2015

Revised 14 December 2015

Accepted for publication 18 December 2015 with organ transplantation. ${ }^{3-5}$ Given the difficulties in diagnosing IFIs due to Candida and Aspergillus and their high mortality rates, prevention strategies and empirical antifungal therapies have been increasingly used in different risk groups. ${ }^{2,6-9}$

In addition the use of antifungal drugs has drastically increased in medical centres throughout the world although this increase is not always compatible with good clinical practice. In fact, some authors have reported a large number of inappropriate prescriptions of antifungal drugs even in teaching hospitals, a factor that increases not only cost and the risk of toxicity but also the possibility of resistance development to antifungal agents. ${ }^{10-13}$ Concurrent with the global increased consumption of antifungal drugs, there has been an increase in the number of reported cases of resistance to different therapeutic antifungal classes among Candida and Aspergillus species. The present 
review will discuss various antifungal resistance patterns that have emerged in these two most important fungal pathogens and will also update about the risk factors and epidemiology of associated fungal infections.

\section{Epidemiology of triazole resistance in Candida spp. and Aspergillus spp.}

In IFI involving Candida, the gradual use of fluconazole and other triazoles in therapeutic regimens for prophylaxis, empirical therapy and diagnostic-driven therapy has led to the development of selective pressure with the emergence of less sensitive species and secondary resistance among isolates primarily sensitive to these drugs. ${ }^{14}$ At first, different medical centres worldwide reported the increase in infections due to Candida glabrata and C. krusei among patients previously exposed to triazoles. At present, C. glabrata accounts for $18.1 \%-40.7 \%$ of the cases of candidaemia in the US and $8.5 \%-31.0 \%$ in Europe. ${ }^{15-27}$ Until 2005, epidemiological studies conducted in Brazil reported a low frequency $(<5 \%)$ of candidaemia due to C. glabrata. Recently, consistent with the epidemiology in the northern hemisphere, a substantial increase in cases of fungaemia due to C. glabrata has also been observed in Brazil. In fact, $C$. glabrata has accounted for $11.2 \%-13.1 \%$ of the reported cases of candidaemia in different regions of Brazil. ${ }^{28-30}$ The same phenomenon was recently reported in Saudi Arabia by Omrani et al. [31]. According to these authors, the proportion of $C$. glabrata has significantly increased between January 2003 and December 2012.

Candidaemia surveillance in six countries in Asia namely China, Hong Kong, India, Singapore, Taiwan and Thailand reported C. albicans (41.3\%) as the most common species. ${ }^{32}$ Among non-albicans Candida species C. tropicalis $(25.4 \%)$ was followed by C. glabrata $(13.9 \%)$ and C. parapsilosis (12.1\%). ${ }^{32-34}$ Although the relative distributions of Candida species varied among the countries, the proportion of C. tropicalis among blood isolates was higher in tropical areas (India, Thailand and Singapore) than other geographical regions. Candida parapsilosis accounted for 33\% of candidaemia cases in one Indian hospital, $26 \%$ in a Chinese hospital and $14 \%$ in a Taiwanese hospital. ${ }^{32}$ However C. glabrata and C. krusei contributed to $26 \%$ and $12.2 \%$ candidaemia cases in tropical countries (China, India and Singapore). ${ }^{32}$ Although, most of the Indian studies demonstrate C. albicans as a predominant yeast causing invasive candidiasis, nosocomial $C$. tropicalis candidaemia ranged from $67 \%$ to $90 \%$ in some Indian hospitals. ${ }^{34,35}$ In Qatar, a retrospective analysis covering the period from January 2004 to December 2010 identified 201 episodes of candidaemia, of which $66.2 \%$ was due to non-albicans Candida species. ${ }^{36}$ Similar data were obtained in the United Arab Emirates. In this study, non-albicans Candida species occurred more frequently than C. albicans in adults (67\%), haematological malignancy patients $(58 \%)$ and in cases with break through candidaemia (83\%). ${ }^{37}$

First described in Japan in 2009, C. auris is increasingly encountered from cases of candidaemia especially from the Indian subcontinent. ${ }^{38-41}$ These findings represent the beginning of an epidemiological shift which is different from Western countries where the increase in uncommon Candida species, as C. kefyr and C. lusitaniae, is likely due to broad use of echinocandins. ${ }^{42}$

A second epidemiological change, first described in developed countries, was the increasing occurrence of fluconazole resistance among isolates of the C. parapsilosis complex and C. tropicalis. Recent studies that performed susceptibility tests using reference methods reported variations in resistance rates among C. parapsilosis isolates of $3.4 \%-7.5 \%$ in the US and $0 \%-6 \%$ in Europe. ${ }^{17,18,22,28,43}$ For C. tropicalis, these rates were $2.4 \%-9 \%$ in the US and $1.7 \%-22.0 \%$ in Europe. ${ }^{17,18,20-22,26,28,43}$ Although infrequent, this phenomenon has been documented in some South American countries, as shown in Table 1. In Brazil, the rates of fluconazole dose-dependent susceptibility and/or resistance in C. tropicalis and C. parapsilosis are 0\%-26.8\% and $0 \%-26.9 \%$ respectively. Recently, Pinhati et al. [44] reported a candidaemia outbreak due to fluconazole-resistant $C$. parapsilosis in patients admitted to intensive care units (ICUs) and Souza et al. [45] reported mutations associated with this resistance.

Conceptually, the azole resistance phenotype in Candida spp. results from the combination of more than one resistance mechanism. ${ }^{14}$ Table 2 summarises the major mechanisms of resistance to this class of antifungal drugs.

In IFI involving Aspergillus, two phenomena associated with resistance to antifungal agents were described: (i) increase in the number of infections due to non-Aspergillus fumigatus, including emerging species primarily resistant to triazoles and eventually to amphotericin B; and (ii) occurrence of secondary azole resistance in A. fumigatus isolates. Table 3 summarises the major species of non- $A$. fumigatus and those belonging to the section Fumigati associated with the phenotype of resistance to the main antifungal agents 
Table 1 Distribution of Candida species and epidemiology of fluconazole resistance in Latin America.

\begin{tabular}{|c|c|c|c|c|c|c|c|c|c|c|c|c|c|}
\hline \multirow[b]{2}{*}{ Countries } & \multirow[b]{2}{*}{ Author [Reference] } & \multirow{2}{*}{$\begin{array}{l}\text { Number of } \\
\text { centres }\end{array}$} & \multirow{2}{*}{$\begin{array}{l}\text { Number of } \\
\text { isolates }\end{array}$} & \multicolumn{5}{|c|}{ Species distribution ${ }^{1}(\%)$} & \multicolumn{5}{|c|}{ DDS/Resistance to $\mathrm{FCZ}^{2}(\%)$} \\
\hline & & & & $\mathrm{Ca}$ & $C t$ & $C p$ & Cgla & $C k$ & $\mathrm{Ca}$ & $\mathrm{Ct}$ & $C p$ & Cgla & $\mathrm{Ck}$ \\
\hline $\begin{array}{l}\text { Latin } \\
\text { America }\end{array}$ & Nucci et al. [290] & 21 & 672 & 37.6 & 17.6 & 26.5 & 6.3 & 2.7 & 0.4 & 0 & 1.1 & 100 & 100 \\
\hline Argentina & Córdoba et al. [291] & 41 & 457 & 38.4 & 15.4 & 26 & 4.33 & 0.5 & 0 & 4.2 & 2.5 & 20 & ND \\
\hline Chile & Silva et al. [292] & 13 & 130 & 47 & 14 & 21 & 3 & 1 & 0 & 7 & 4 & 33 & 100 \\
\hline Venezuela & Dolande et al. [293] & 6 & 154 & 46.7 & 19 & 6 & 9.2 & 2.7 & 7.4 & 12.9 & 10 & 43.4 & 96 \\
\hline Colombia & Maldonado et al. [294] & 15 & 300 & 48.3 & 22.3 & 15 & 6.7 & 2.7 & 7.6 & 10.3 & 24.4 & 100 & 100 \\
\hline Mexico & Corzo-Leon et al. [295] & 2 & 74 & 46 & 26 & 5 & 13.5 & 5 & 0 & 0 & 0 & 11 & ND \\
\hline Brazil & Aquino et al. [296] & 1 & 131 & 45 & 15.3 & 24.4 & 6.9 & 4.6 & 0 & 0 & 0 & 45 & 100 \\
\hline Brazil & Colombo et al. [297] & 11 & 712 & 40.9 & 20.9 & 20.5 & 4.9 & 1.1 & 0.3 & 0 & 0 & 6 & 37.5 \\
\hline Brazil & $\begin{array}{l}\text { Bruder-Nascimento } \\
\text { et al. [298] }\end{array}$ & 1 & 212 & 33 & 17.9 & 31.1 & 11.8 & 0 & 7.1 & 18.4 & 1.5 & 68 & ND \\
\hline Brazil & Colombo et al. [29] & 9 & 300 & 34 & 24 & 26 & 7 & 3 & 0 & 3 & 0 & 64 & 100 \\
\hline Brazil & Santos et al. [299] & 1 & 422 & 35.7 & 9.71 & 46.6 & 3.5 & 0.9 & 9.9 & 26.8 & 7.1 & 100 & 100 \\
\hline Brazil & da Costa et al. [300] & 1 & 93 & 28.7 & 30.5 & 24.1 & 8.3 & 1.8 & 3.7 & 3.2 & 26.9 & 0 & ND \\
\hline
\end{tabular}

${ }^{1}$ Ca, C. albicans; Cd, C. dubliniensis; Ct, C. tropicalis; Cgla, C. glabrata; Cp, C. parapsilosis; Ck, C. krusei; Cgui, C. guilliermondii; FCZ, fluconazole; DDS, dose-dependent susceptibility; ND, not determined.

${ }^{2}$ Rates of DDS/Resistance to FCZ reflects the breakpoints available in that particularly period.

Table 2 Mechanisms of azole resistance in different Candida species.

\begin{tabular}{|c|c|c|c|c|c|c|c|c|}
\hline \multirow[b]{2}{*}{ Mechanism } & \multirow[b]{2}{*}{ Due to: } & \multirow[b]{2}{*}{ Result } & \multicolumn{6}{|c|}{ Occurrence in Candida species ${ }^{1}$} \\
\hline & & & $\mathrm{Ca}$ & $C d$ & $\mathrm{Ct}$ & Cgla & $C p$ & $\mathrm{Ck}$ \\
\hline $\begin{array}{l}\text { Decrease in the } \\
\text { intracellular concentration }\end{array}$ & $\begin{array}{l}\text { - Expression of } \\
A B C \text { transporters }\end{array}$ & Drug efflux & ++ & + & + & ++ & ++ & ++ \\
\hline of the target enzyme & $\begin{array}{l}\text { - Expression of } \\
\text { MF transporters }\end{array}$ & & ++ & ++ & + & + & ++ & ND \\
\hline Changes in the drug target & $\begin{array}{l}\text { Mutations in the } \\
\text { ERG11 gene }\end{array}$ & $\begin{array}{l}\text { Decreased affinity } \\
\text { of the target enzyme } \\
\text { for the azole }\end{array}$ & ++ & ++ & ++ & + & ++ & ++ \\
\hline $\begin{array}{l}\text { Increased production of } \\
\text { lanosterol } 14 \alpha \text {-demethylase }\end{array}$ & Multiple factors ${ }^{2}$ & $\begin{array}{l}\text { Increased synthesis } \\
\text { of ergosterol }\end{array}$ & ++ & ++ & ++ & ++ & ++ & ++ \\
\hline
\end{tabular}

${ }^{1}$ Ca, C. albicans; Cd, C. dubliniensis; Ct, C. tropicalis; Cgla, C. glabrata; Cp, C. parapsilosis; Ck, C. krusei; +, mechanism not yet observed in clinical isolates; ++, mechanism observed in clinical isolates; ND, mechanism not yet described.

${ }^{2}$ gene duplication, mutations in the promoter gene or mutations in the gene encoding the target enzyme.

commonly used in clinical practice. ${ }^{46-49}$ The rate of infection due to emerging species of Aspergillus is not fully known because only a few case series have performed accurate molecular identification, such as DNA sequencing of Aspergillus at the species level. However, there are a substantial number of case series on A. flavus, A. lentulus and A. terreus. ${ }^{50-52}$ Primary resistance to amphotericin $\mathrm{B}$ (AMB) is well known in A. terreus, however, in a recent study by Kathuria et al. [52] low AMB minimum inhibitory concentration (MIC) (range $0.5-1 \mathrm{mg} / \mathrm{L}$ ) in $8 \%$ of Indian A. terreus isolates were observed. Furthermore, in some isolates of A. flavus and A. ustus also amphotericin B resistance was reported. ${ }^{53-55}$ More recently, this phenomenon has been demonstrated in several species of the section Fumigati, including A. fumigatiaffinis and A. lentulus. ${ }^{44,46,48,49,56}$

Secondary azole resistance in Aspergillus has been well documented among isolates of $A$. fumigatus. ${ }^{12,57}$ Acquired azole resistance has been reported also in $A$. flavus and A. terreus, although there is no evidence of developing acquired resistance to other antimycotic drugs in other species of this genus. ${ }^{46,48,56,58,59}$

Table 4 summarises the key studies that determined the rates of azole resistance in clinical isolates of $A$. fumigatus. The resistance rate varied between $0.6 \%$ 
and $29.6 \%$, and the lowest rate was observed in isolates from the US, where resistance was $<1 \%$ and mutations in the CYP51A are rare. ${ }^{12,60,61}$ Although triazole resistance is still considered unusual, with rates of $<5 \%$ in many countries, azole resistance in $A$. fumigatus seems to be increasing in several European countries, and high rates have been observed primarily in medical centres in Denmark (4.5\%), France $(0.8 \%-8 \%)$ and UK $(6 \%-27 \%){ }^{47,62-67}$ In these countries, particularly in the UK (specifically in Manchester), high resistance rates $(6 \%-27 \%)$ have been reported among patients with chronic cavitary aspergillosis who used triazoles for long periods. ${ }^{68,69}$ To find the proper empirical treatment of invasive aspergillosis in areas with a high rate of azole resistance is challenging especially in patients with chronic pulmonary aspergillosis. ${ }^{12,70}$

A second epidemiological model of the development of triazole resistance in A. fumigatus has been described in the Netherlands, where the rates of resistance to these drugs vary between $1.7 \%$ and $30 \%$ in patients not previously exposed to antifungal therapy, thus suggesting a possible environmental route for the development of triazole resistance ${ }^{67,71-75}$ An epidemiological study conducted in Japan involving 196 clinical isolates reported that $11.2 \%$ of the isolates were resistant to triazoles. ${ }^{76}$

In Brazil, only two studies reported the prevalence and rates of triazole resistance among emerging species of non- $A$. fumigatus. These studies reported higher MIC values to these drugs among isolates of $A$. calidoustus, A. clavatus, A. tamarii, A. nomius, A. ochraceus and A. terreus. ${ }^{54,77}$

The rate of azole resistance in clinical A. fumigatus isolates in India was found to be $1.7 \%-1.9 \%{ }^{57,78-80}$ However, in China the ARTEMIS global sentinel surveillance programme demonstrated a pan-azoleresistant phenotype in $27.5 \%$ of A. fumigatus isolates. $^{81}$ In contrast, Japan reported $5.2 \%$ azole-resistant A. fumigatus isolates. ${ }^{76,82}$ A similar range of resistance prevalence of $3.2 \%$ and $12.5 \%$ A. fumigatus isolates was observed in clinical samples from chronic pulmonary aspergillosis (CPA) and allergic bronchopulmonary aspergillosis (ABPA) patients from Iran and Kuwait respectively. ${ }^{83,84}$

\section{Molecular mechanisms of azole resistance in Candida spp. and Aspergillus spp.}

Azoles inhibit enzymes involved in the final stages of ergosterol biosynthesis, particularly lanosterol $14 \alpha$ demethylase. Therefore, sterol precursors - including methylated sterols - accumulate in the cell, resulting in cell membrane instability and consequent fungal growth impairment. ${ }^{85-87}$

In Candida and Aspergillus, azole resistance appears to be associated with three major molecular mechanisms, which will be discussed in this review.

Table 3 Primary resistance among Aspergillus species.

\begin{tabular}{|c|c|c|c|c|}
\hline Species & Invasive disease & Resistance profile & Section & References \\
\hline A. lentulus & Relatively common & $\begin{array}{l}\text { Primary resistance to } A M B \text {, } \\
\text { azoles and varied resistance to CFG }\end{array}$ & Fumigati & {$[48,301-304]$} \\
\hline A. udagawae & Rare & Primary resistance to $\mathrm{AMB}$ and $\mathrm{VRC}$ & Fumigati & {$[66,301,302,305,306]$} \\
\hline N. pseudofisheri & Rare & $\begin{array}{l}\text { Varied susceptibility to AMB and } \\
\text { lower susceptibility to azoles }\end{array}$ & Fumigati & {$[48,302,307]$} \\
\hline A. fumigatiaffinis & Not reported & $\begin{array}{l}\text { Primary resistance to AMB and lower } \\
\text { resistance to azoles }\end{array}$ & Fumigati & [49] \\
\hline A. viridinutans & Rare & Lower susceptibility to AMB and azoles & Fumigati & {$[48,308]$} \\
\hline A. flavus & Relatively common & $\begin{array}{l}\text { Primary resistance to AMB and varied } \\
\text { susceptibility to CFG }\end{array}$ & Flavi & {$[54,66,302,309-313]$} \\
\hline A. allilaceus & Relatively common & Lower susceptibility to AMB and CFG & Flavi & {$[302,314-317]$} \\
\hline A. terreus & Relatively common & Primary resistance to $\mathrm{AMB}$ & Terrei & {$[66,276,280,318-321]$} \\
\hline A. alabamensis & Not reported & Primary resistance to $\mathrm{AMB}$ & Terrei & [322] \\
\hline A. niger & Rare & Varied and lower susceptibility to azoles & Nigri & {$[60,310,323-325]$} \\
\hline A. calidoustus & Rare & $\begin{array}{l}\text { Primary resistance to AMB and azoles and } \\
\text { varied susceptibility to CFG }\end{array}$ & Ustis & {$[77,302,326,327]$} \\
\hline A. versicolor & Rare & $\begin{array}{l}\text { Varied susceptibility to AMB and lower } \\
\text { susceptibility to azoles }\end{array}$ & Nidulantes & {$[302,325,328]$} \\
\hline A. sydowii & Rare & $\begin{array}{l}\text { Varied susceptibility to AMB and lower } \\
\text { susceptibility to azoles }\end{array}$ & Nidulantes & {$[60,302,328]$} \\
\hline
\end{tabular}

AMB, amphotericin B; CFG, caspofungin; IA, invasive aspergillosis; VRC, voriconazole. 
Table 4 Rates of triazole resistance in clinical isolates of Aspergillus fumigatus.

\begin{tabular}{|c|c|c|c|c|c|}
\hline Countries & Study period & Number of samples & Resistance rate (\%) & Methodology & References \\
\hline UK (single centre) & 1997-2007 & 519 & 6.6 & EUCAST & [68] \\
\hline UK (single centre) & 2008-2009 & 230 & 27.8 & EUCAST & [69] \\
\hline The Netherlands (multicentre) & 1945-1998 & 170 & 1.7 & CLSI M38-P & [71] \\
\hline The Netherlands (single centre) & 1994-2007 & 2061 & 3.1 & CLSI M38-A & [67] \\
\hline The Netherlands (multicentre) & 2007-2009 & 1792 & 4.6 & ITZ agar & [72] \\
\hline The Netherlands (multicentre, 8 centres) & 2009-2011 & 921 & 6.8 & 4D plates ${ }^{1}$ & [73] \\
\hline The Netherlands (multicentre) & 2010-2013 & 952 & 24 & EUCAST & [74] \\
\hline Spain (multicentre, 29 centres) & 2010-2011 & 156 & 0.6 & EUCAST & [65] \\
\hline Spain (single centre) & 1999-2011 & 353 & 4.2 & CLSI (M38-A2) & [328] \\
\hline France (single centre) & 2006-2009 & 118 & 0.8 & Etest $^{\circledR}$ & [329] \\
\hline France (single centre) & $2010-2011$ & 85 & 8.0 & EUCAST & [183] \\
\hline Germany (single centre) & 2011-2012 & 527 & 3.2 & EUCAST & [141] \\
\hline Germany (multicentre) & 2010-2013 & 526 & 1.1 & EUCAST & [64] \\
\hline Germany (multicentre) & $2012-2013$ & 27 & 29.6 & Etest $^{\circledR}$ & [157] \\
\hline Denmark (single centre) & 2007 and 2009 & 133 & 4.5 & EUCAST & [177] \\
\hline Japan (single centre) & 1994-2010 & 196 & 11.2 & CLSI (M38-A2) & [76] \\
\hline India (single centre) & 2005-2010 & 103 & 1.9 & CLSI (M38-A2) & [330] \\
\hline Iran (single centre) & $2003-2009$ & 124 & 3.2 & CLSI M38-A & [82] \\
\hline US (multicentre, 23 centres) & $2001-2006$ & 181 & 0.6 & CLSI (M38-A2) & [66] \\
\hline
\end{tabular}

${ }^{1}$ Triazoles diluted in agar; CLSI, Clinical Laboratory Standard Institute; ITZ, itraconazole; EUCAST, European Committee on Antimicrobial Susceptibility Testing.

\section{Decrease in the intracellular drug concentration}

The activation of efflux pumps located in the cell membrane has already been described as an important mechanism of resistance to antifungal agents in Candida spp. Two different drug efflux systems have been associated with azole resistance: (i) the ATP-binding cassette $(\mathrm{ABC})$ protein superfamily, and (ii) the major facilitator superfamily (MFS) of transporters.

Proteins belonging to the $\mathrm{ABC}$ superfamily are primary transporters that hydrolyse ATP molecules and are essential for substrate transport. Many ABC transporters with different topologies have been described in fungal species. In C. albicans, it is believed that there are 28 types of transporters, and although their role in azole resistance is not fully understood, two transporters - Candida drug resistance 1 (CDR1) and Candida drug resistance 2 (CDR2) - are well characterised. ${ }^{15,88,89}$

Sanglard et al. [90] reported that the deletion of both alleles in the CDR 1 gene in $C$. albicans resulted in increased intracellular levels of fluconazole. Moreover, this mutant is hypersensitive to azoles, terbinafine, amorolfine and several other metabolic inhibitors, including cycloheximide, brefeldin A and fluphenazine. Azole-resistant $C$. albicans isolates showed high CDR2 gene expression levels, even higher than the CDR1 expression levels. Furthermore, the concomitant deletion of CDR1 and CDR2 resulted in increased susceptibility to azoles. ${ }^{88}$ Other studies in agreement with these findings have shown that CDR 1 and CDR2 overexpression plays an important role in the azole resistance phenotype observed in clinical isolates of $C$. albicans. $^{91-94}$

In other Candida species, functional homologues of CDR 1 and CDR 2 and other genes encoding ABC transporters have been described and were associated with drug resistance, including CgCDR1, CgCDR2 (also known as PDH1) and CgSNQ2 in C. glabrata; CdCDR1 and CdCDR2 in $C$. dubliniensis and $A B C 1$ in $C$. krusei. $^{15,95-102}$ In C. tropicalis, isolates with in vitroinduced resistance showed overexpression of CtCDR 1. ${ }^{103}$ However, this profile was not observed in clinical isolates of C. tropicalis. ${ }^{104,105}$ In C. parapsilosis, Silva et al. [106] reported the increased expression of CDR 1 in isolates with induced resistance to fluconazole due to the expression of the transcription factor Ndt80. In C. albicans, Ndt80 is involved in CDR 1 regulation. In addition, this transcription factor binds to a wide range of genes with diverse biological functions, including other transporter factor, as well as genes that encode ergosterol biosynthesis enzymes. ${ }^{107,108}$

The second efflux system associated with azole resistance involves MFS transporters, which transport various substrates using the proton gradient generated in the plasma membrane. ${ }^{89,109}$ On the basis of in silico analysis, 95 MFS transporters are believed to occur in C. albicans. Of these, only the product of the multidrug 
resistance 1 (MDR1) gene has been associated with azole resistance in clinical isolates. ${ }^{15}$ Importantly, unlike CDR 1 and CDR2 overexpression, which culminates in resistance to various azoles, MDR1 overexpression leads to resistance to fluconazole alone and does not appear to be associated with cross-resistance among the azoles. ${ }^{15,89}$ Different mechanisms are involved in MDR1 regulation, including the transcription factor Mrr1 (multidrug-resistance regulator 1). ${ }^{14}$ Inactivation of MRR1 in clinical C. albicans strains blocked MDR1 expression. ${ }^{110}$ Gain-of-function mutations in MRR1 causing constitutive up-regulation of MDR1 have been reported in different Candida species. ${ }^{111-113}$

Wirsching et al. [114] using gene deletion techniques, found that $C$. albicans isolates without the MDR1 gene were extremely susceptible to fluconazole. In fact, the correlation between MDR1 overexpression and the fluconazole resistance phenotype has been previously demonstrated..$^{93,94,115,116}$

MDR1 homologues genes have been found in different species of Candida. Although the CgFLR1 gene confers resistance to fluconazole when expressed in Saccharomyces cerevisiae, the actual role of this gene in the resistance phenotype in C. glabrata isolates is not known. ${ }^{89,97}$ In C. dubliniensis, the MDR1 gene appears to play an important role in azole resistance. ${ }^{95,115,117}$ In C. tropicalis, no association was found between drug resistance of clinical isolates and MDR1 overexpression. ${ }^{104,105}$ In C. parapsilosis, MDR1 expression has been associated with a fluconazole resistance phenotype. ${ }^{106,113}$

Much less is known about the role of efflux pumps in resistance development in Aspergillus species compared with the number of studies on resistance in Candida. Most studies used A. fumigatus as a reference, and genes coding for efflux transporters are abundant in this species. On the basis of in silico analysis, at least 50 genes encoding $\mathrm{ABC}$ transporters and 300 genes encoding MFS transporters were predicted in the genome of this fungal species. ${ }^{118,119}$ Despite the large number of genes encoding these transporters, little is known about the association between gene overexpression and triazole resistance in A. fumigatus. In this species, the overexpression of the transporter genes AfuMDR1, AfuMDR2, AfuMDR3, AfuMDR4 and ATRF is associated with triazole resistance. ${ }^{119,120}$ The ATRF gene product (AtrF) is 1547 amino acids sequence and has characteristic MDR motifs. ${ }^{121}$ The AfuMDR4 gene is also involved in drug resistance of biofilms produced by A. fumigatus. ${ }^{118} \mathrm{Da}$ Silva Ferreira et al. [121] reported the expression of five $\mathrm{ABC}$ transporters (abcA-E) and three MFS transporters $(\mathrm{mfs} A-\mathrm{C})$ in response to the in vitro induction of voriconazole resistance in a clinical, azole susceptible, isolate. However, to date, the association between these findings and clinical resistance to azoles has not been fully elucidated.

Among the transporters characterised in drug-resistant clinical isolates of $A$. fumigatus, the levels of CDR1B have been most consistent and prominently overexpressed. In fact, the mRNA expression levels for CDR1B were 5- to 30-fold higher in these isolates. CDR1B deletion also resulted in a 4-fold increase in the susceptibility to itraconazole in isolates both resistant and susceptible to this drug. ${ }^{122}$ Of note, the data available on the effect of efflux pumps on the decrease in the susceptibility of $A$. fumigatus to azoles were obtained from studies on resistance induced in vitro and not from clinical isolates for which resistance was acquired during infection of human hosts. ${ }^{122}$

\section{Changes in the target site of the drug (ERG11/CYP51)}

The inhibitory activity of triazoles via changes in the target site has been described as a frequent cause of resistance. In this setting, non-synonymous mutations in ERG11 (CYP51 for Aspergillus) can change the three-dimensional structure of lanosterol 14ademethylase, resulting in decreased affinity of this molecule to azoles and, consequently, decreased inhibition of ergosterol biosynthesis. ${ }^{15,123,124}$

According to Morio et al. [125], more than 140 types of substitutions in the amino acid sequence of ERG11 have been described in C. albicans. However, few of these substitutions have been associated with azole resistance and, when present, may not contribute to the same extent to the development of the phenotype of resistance to this drug class. To address this hypothesis, some of these substitutions, including K143R, S405F, G464S, I471T and R467K, were described only in azole-resistant isolates, whereas others, including E266D and V488I, were observed in isolates both resistant and susceptible to azoles and, therefore, do not appear to contribute to the resistance phenotype. ${ }^{125-130}$

Mutations in ERG11 have also been described in other species of Candida, including C. dubliniensis, C. krusei, C. tropicalis and, more recently, C. kefyr and C. parapsilosis. ${ }^{104,105,113,131-134}$ Although the primary mechanism involved in azole resistance appears to be the expression of efflux pumps, Hull et al. [135] reported the presence of a non-synonymous mutation in ERG11 in a clinical C. glabrata isolate with crossresistance between azoles and amphotericin $\mathrm{B}$. 
Unlike yeasts, Aspergillus has two distinct genes CYP51A and CYP51B - that encode Cyp51. Most studies indicate that point mutations in the CYP51A gene in A. fumigatus confer resistance to triazoles and innate resistance to fluconazole. ${ }^{136}$ In contrast, CYP51B is associated with the growth rate and maintenance of the fungal cell, but its role in the susceptibility to azoles is still unclear. ${ }^{49}$ Clinical data suggest that CYP51A has an important role in regulating the activity of 14- $\alpha$-demethylase, whereas CYP51B is a redundant gene whose expression becomes important only in the absence of CYP51A. ${ }^{136,137}$

Specific mutations in CYP51A may confer resistance to one, two or all triazoles, and various mutations in this gene have been described in clinical isolates and laboratory-generated mutants. ${ }^{63,138}$ Nonsynonymous point mutations are reported more frequently in this gene, particularly in codons 54, 98, 138, 220, 431, 434 and 448. ${ }^{72,139}$ Among these mutants, isolates with changes in codons 98, 138, 431, 434 and 448 generally have the pan-azole resistance phenotype, i.e. resistance to all azoles. ${ }^{68}$ Denning et al. [140] evaluated 25 sputum samples positive for Aspergillus from patients with chronic pulmonary aspergillosis and allergic bronchopulmonary aspergillosis and detected mutations in codon M220 in four $(16 \%)$ samples. Three of the four patients with this marker experienced treatment failure when itraconazole and/or posaconazole were used. To date, more than 30 different point mutations in CYP51A conferring azole resistance in $A$. fumigatus have been identified. $^{141-143}$

Another type of azole resistance mechanism that occurs very frequently is a tandem repeat in a 34-bp sequence in the promoter region $\left(\mathrm{TR}_{34}\right)$ of the CYP51A gene. This mechanism, combined with a leucine to histidine substitution at codon 98 (L98H), resulted in increased CYP51A expression. ${ }^{63,67,144,145}$ This mutation is probably associated with use of azole fungicides in agriculture and was first reported in Europe. ${ }^{67}$ The same resistance mechanism was subsequently reported in clinical and environmental azoleresistant A. fumigatus from all over the world including Africa, Americas, Asia, Australia and the Middle East. $^{12,57,80,146,147}$ In contrast, more recently few studies from Japan, described azole resistance in clinical A. fumigatus isolates but interestingly none of them exhibited $\mathrm{TR}_{34} / \mathrm{L} 98 \mathrm{H}$ resistance mechanism, instead several SNPs and novel mutations, F332K and P216L were reported. ${ }^{148,149}$ A single centre study from Japan reported 5.2\% azole-resistant isolates harbouring only G54E/R/W and I266N mutation. ${ }^{76,82}$
Recently, a novel mechanism of resistance involving the tandem repeat of a 46-bp sequence $\left(\mathrm{TR}_{46}\right)$, together with the substitution of a few amino acids (Y121F/T289A), was associated with treatment failure in patients using voriconazole in the Netherlands. ${ }^{73}$ In addition to Belgium and the Netherlands, clinical and environmental isolates carrying the $\mathrm{TR}_{46} / \mathrm{Y} 121 \mathrm{~F} /$ T289A mutation have been identified in China, Colombia, Denmark, France, Germany, India, Spain, Tanzania and US. ${ }^{12,64,150-158}$ The $\mathrm{TR}_{34} / \mathrm{L9} 8 \mathrm{H}$ mutation induces pan-azole resistance, whereas the $\mathrm{TR}_{46} /$ Y121F/T289A mutation induces high resistance to voriconazole. $^{73,74,151-156}$

Hodiamont et al. [159] evaluated a patient with chronic granulomatous disease and osteomyelitis due to A. fumigatus and found a mutation associated with the tandem repeat of a 53-bp sequence in the promoter region of CYP51A in this species. However, this mutation did not involve any amino acid substitution. It is of note that the patient received prophylaxis with itraconazole and that the isolate showed resistance to itraconazole and voriconazole and lower susceptibility to posaconazole. This same $\mathrm{TR}_{53}$ has recently been found in resistant environmental $A$. fumigatus isolates from Colombia. ${ }^{158}$

In fact, not all isolates with increased MIC values have a mutation in the CYP51A gene, and not every mutation implies fungal resistance to antifungal agents. $^{67}$

\section{Increased production and inhibition of the target enzyme by the drug}

The increased production of ergosterol due to the increase in the expression of the ERG11 gene (CYP51) constitutes a common azole-resistance mechanism in C. albicans and A. fumigatus. ${ }^{92-94,123,160}$ In C. albicans, two mechanisms are associated with ERG11 overexpression: (i) an increase in the expression of the transcription factor Upc2, which is responsible for regulating the expression of most genes involved in ergosterol biosynthesis; and (ii) formation of an isochromosome with two copies of the left arm of chromosome 5, where the ERG11 gene is located, or full duplication of the chromosome. ${ }^{14}$

The association between increased expression of ERG11 and azole resistance has also been reported in C. dubliniensis, C. glabrata, C. krusei, C. parapsilosis and C. tropicalis. ${ }^{45,105,113,131,161-163}$

In A. fumigatus, the increased production of ergosterol may be associated with the transcriptional regulation of the CYP51A gene, and this regulation 
may be mediated by both transcription factors and tandem repeats in the promoter regions. SrbA, a transcriptional regulator belonging to the sterol regulatory element binding protein (SREBP) family, has important implications in triazole resistance in Aspergillus. ${ }^{164}$ The deletion of the SRBA gene in A. fumigatus induces hyper susceptibility to azoles and increases fungal susceptibility to fluconazole. This phenomenon may be associated with decreased expression of the CYP51A gene in the absence of SrbA because isolates with repressed CYP51A also exhibited increased susceptibility to this drug. ${ }^{136,165,166}$

Recently, the complete genome sequences of two inbred isolates of $A$. fumigatus (one susceptible and one resistant) isolated from immunocompromised patients with chronic pulmonary aspergillosis were used to identify mutations that confer azole resistance. This study identified several non-synonymous mutations. However, only the mutation in the transcription factor associated with the CCAAT-sequence in a subunit of the HapE complex conferred resistance of this progeny to azoles by increasing the CYP51A gene expression levels. ${ }^{167}$ CCAAT-sequences are present in the promoters of a large number of eukaryotic genes. In general, they are formed by approximately 50- to 200-bp sequences upstream of the transcription initiation site and may occur in any orientation of the gene. These sequences are attached to different transcription factors, which can explain the diversity of functions associated with the modulation of the transcription levels in eukaryotic cells. ${ }^{168}$ Coincidentally, the CCAAT-sequence is present in the promoter of the CYP51A gene. Therefore, the hapE mutant can induce the increase in the expression of the CYP51A mRNA, demonstrating that transcription factors can regulate the expression of these genes. ${ }^{167}$ However, to date, these changes have not yet been described among resistant clinical isolates.

\section{Risk factors for the development of candidaemia by fluconazole-resistant isolates}

The first epidemiological studies that assessed the risk for developing bloodstream infection (BI) due to $C$. glabrata and C. krusei, which are intrinsic resistant to fluconazole, provided clinicians with information necessary for the early detection of patients at risk of developing IFIs due to fluconazole-resistant Candida isolates. In these cases, the independent variables associated with BI due to C. glabrata included the previous use of fluconazole or caspofungin, recent exposure to metronidazole, surgical procedures, the presence of central venous catheter (CVC) position, cancer, mechanical ventilation and senescence. ${ }^{169-171}$ For infections due to C. krusei, the independent risk factors included previous exposure to fluconazole or caspofungin, neutropenia, solid tumours, organ transplantation, splenectomy and use of antibiotics with antianaerobic coverage. ${ }^{170-172}$

Over the past few years, an increase in the number of cases of candidaemia due to fluconazole-resistant isolates belonging to species primarily sensitive to this drug, including $C$. parapsilosis and $C$. tropicalis were noted. ${ }^{17,18,20-22,26,28,38,44}$ Several studies have explored the predisposing factors for the development of candidaemia due to fluconazole-resistant Candida species.

In this scenario, Garnacho-Monteiro et al. [173] observed that neutropenia, chronic kidney disease and previous exposure to fluconazole were independent risk factors for the isolation of fluconazole-resistant Candida isolates. Recently, Cuervo et al. [174], on the basis of clinical data easily obtained at the bedside, developed and validated a score that allows for the estimation of the risk of candidaemia due to fluconazole-non-susceptible (Flu-NS) isolates. The multivariate analysis indicated that the following variables were classified as risk factors for fluconazole resistance: previous use of azoles for 3 days, hospitalisation in units with a prevalence of candidaemia due to Flu-NS isolates $>15 \%$, and previous history of transplantation.

\section{Risk factors for resistance development in $A$. fumigatus worldwide: epidemiological model in the Netherlands and the UK}

High rates of triazole resistance in A. fumigatus were reported in the Netherlands and in the UK. ${ }^{68}$ The first clinical case of resistance to itraconazole was reported in 1997. ${ }^{175}$ In 2000, Moore et al. [70,176] tested the susceptibility of more than 900 isolates to amphotericin B and itraconazole. The percentage of patients harbouring A. fumigatus isolates resistant to this drug class increased to $15 \%$ in 2007 and to $20 \%$ in 2009 . In the Netherlands, azole resistance increased dramatically from $2.5 \%$ in 2000 , to $4.9 \%$ in 2002 , to $6.6 \%$ in 2004, to $10 \%$ in $2009 .{ }^{46}$ By 2013 in certain centres resistance rates of up to $15 \%$ are found in high risk haematology patients. ${ }^{75}$ This trend represents a yearly increase of $6 \%$, and in this case, the patients were infected by resistant isolates but without prior exposure to antifungal therapy. ${ }^{62}$ Therefore, although higher rates of resistance in A. fumigatus were described in the Netherlands and the UK (Manchester), 
it is essential to recognise that the mode of resistance development had distinct determinants in these countries.

In Manchester, where the National Aspergillosis Centre is located, the hypothesis of resistance is attributed to the use of long-term antifungal therapy in patients with chronic forms of pulmonary aspergillosis, more specifically, aspergilloma and chronic cavitary aspergillosis. In the latter case, some researchers suggested the occurrence of microevolution of the fungus in the lung tissue because both sensitive and resistant isolates with identical or closely related genotypes were reported to infect the same patient. ${ }^{177,178}$

In the Netherlands, the occurrence of triazole resistance in Aspergillus is closely associated with so called environmental mutations. It is believed that the use of azoles as fungal pesticides has led to the emergence of mutations in the CYP51A gene. ${ }^{46,57}$ From approximately 30 azole fungicides commonly used in agriculture, seven showed cross-resistance with azoles in clinical use. ${ }^{79,179}$ Two resistance mechanisms associated with point mutations in CYP51A $\left(\mathrm{TR}_{34} / \mathrm{L} 98 \mathrm{H}\right.$ and $\mathrm{TR}_{46 /} \mathrm{Y} 121 \mathrm{~F} / \mathrm{T} 289 \mathrm{~A}$ ) have been reported in clinical and environmental isolates, and the latter were recovered from patients not exposed to antifungal agents. ${ }^{151-153}$

An increasing number of cases involving azole-resistant environmental isolates of $A$. fumigatus have been documented in Asia and Europe. ${ }^{78,79,83,180}$ It is suggested that most of the clinical cases of resistance reported between 2009 and 2011 from Dutch patients were due to the dissemination of resistant environmental isolates. ${ }^{181}$ Between 2012 and 2015, other countries, including Austria, Belgium, Denmark, France, Germany, Ireland, Poland, Spain, Sweden and the UK, also reported the identification of clinical isolates of A. fumigatus harbouring the $\mathrm{TR}_{34} / \mathrm{L} 98 \mathrm{H}$ mutation. ${ }^{12,65,141,152,181-183}$

The wide geographical distribution of the $\mathrm{TR}_{34} /$ L98H mutation has raised questions about the origin of azole-resistant Aspergillus isolates, including (i) the geographical migration of resistant conidia carrying this mutation, (ii) the independent local development of this mutation and subsequent selection of the $\mathrm{TR}_{34} /$ L98H mutation in unrelated isolates and (iii) the previous two hypotheses occurring simultaneously. ${ }^{144}$ To clarify the origin and dissemination of this genotype, Camps et al. [181], using molecular markers, evaluated the genetic relationship of 142 European isolates recovered between 1998 and 2007. The authors noted that the isolates with the $\mathrm{TR}_{34} / \mathrm{L} 98 \mathrm{H}$ resistance mechanism showed less genetic variation compared with wild-type susceptible isolates or with those with other resistance mechanisms. In addition, the crossing of these isolates indicated that the $\mathrm{TR}_{34} / \mathrm{L} 98 \mathrm{H}$ isolates could cross with azole susceptible isolates of different genetic origins, suggesting that $\mathrm{TR}_{34} / \mathrm{L} 98 \mathrm{H}$ isolates could complete their natural sexual cycles. This finding suggests the occurrence of a common ancestry for the $\mathrm{TR}_{34} / \mathrm{L} 98 \mathrm{H}$ mechanism. ${ }^{181}$

Chowdhary et al. [79] evaluated nine loci in azoleresistant and susceptible isolates from India and observed the occurrence of a wide genetic diversity among environmental and clinical isolates susceptible to azoles, and these isolates were highly polymorphic. The azole-resistant isolates harbouring the $\mathrm{TR}_{34} / \mathrm{L} 98 \mathrm{H}$ mutation shared the same genotype, indicating clonal propagation. However, this genotype was not detected in other isolates from other countries, such as China, France, Germany and the Netherlands. Therefore, the authors suggested that the Indian genotype was an adaptive recombinant progeny derived from the crossing between an azole-resistant isolate (that migrated into India) and an azole-sensitive isolate (that was native to India); this crossing underwent mutation and quickly dispersed to various parts of India. ${ }^{78}$

Of note, $61 \%$ of the global agricultural fungicide market is concentrated in Western Europe and Asia, suggesting that the prevalence of the $\mathrm{TR}_{34} / \mathrm{L} 98 \mathrm{H}$ mutation in the CYP51A gene is directly associated with geographical parameters and the indiscriminate use of these antifungal fungicides. ${ }^{184}$

With regard to the emerging $\mathrm{TR}_{46} / \mathrm{Y} 121 \mathrm{~F} / \mathrm{T} 289 \mathrm{~A}$ mutation, to date, clinical isolates carrying this mutation have been detected in China, Belgium, Denmark, France, Germany, the Netherlands, Spain and the US, whereas environmental isolates with this mechanism have been reported in Belgium, Colombia, France, Germany, India, the Netherlands and Tanzania. ${ }^{12,64,150-}$ $152,157,158,184$

At this point, an increased concern about the rapid spread of isolates harbouring these two mutations should be underscored because these cases have been reported in hospitals and homes throughout Europe. ${ }^{12,73}$ Furthermore, the exposure of A. fumigatus to azole fungicides can induce the emergence of novel resistance mechanisms over time, thereby compromising the clinical use of azoles in the treatment of diseases associated with Aspergillus.

\section{Rates of echinocandin resistance in Candida spp. and Aspergillus spp. worldwide}

Echinocandins represent the most recent antifungal class, consisting of three agents - micafungin, 
anidulafungin and caspofungin - that act by inhibiting cell wall synthesis. Caspofungin was the first echinocandin approved by the Food and Drug Administration (FDA) in 2001 in the US, followed by micafungin and anidulafungin, which were approved in 2005 and 2006, respectively, and the three drugs are available only in parenteral preparations. ${ }^{185-187}$ Since their introduction, echinocandins have been widely used for the treatment and empirical therapy of fungal infections due to Candida and Aspergillus. ${ }^{188-190}$ Although echinocandin resistance is still considered unusual, cases of resistance by using this therapeutic class have become increasingly frequent. ${ }^{42,191}$

Recently, Cleveland et al. [192] conducted a surveillance study in two US cities between 2008 and 2013 involving invasive candidiasis in a prospective cohort. In this series, increases in cases of echinocandin resistance were observed in Atlanta (from $1.2 \%$ to $2.9 \%$, a $147 \%$ increase) and Baltimore ( $2 \%$ to $3 \%$, a $77 \%$ increase). In addition the authors reported that $44 \%$ of the multidrug-resistant isolates that exhibited an echinocandin- and fluconazole resistance phenotype were recovered from patients without prior exposure to echinocandins, suggesting the occurrence of horizontal transmission of this resistant phenotype.

Although this resistance mechanism remains uncommon in isolates of C. albicans, C. krusei and C. tropicalis, echinocandin resistance has become increasingly common among isolates of C. glabrata and other species such as C. lusitaniae and C. kefyr. ${ }^{42,193}$ Recently, Alexander et al. [194] reported that in the US, the resistance rate of C. glabrata isolates increased from $4.9 \%$ to $12.3 \%$ between 2001 and 2010. In Europe, the same trend is observed, although on a smaller scale. Accordingly, a study reported that the resistance rate of C. glabrata isolates increased from $0 \%$ to $3.1 \%$ between 2004 and 2013 in Denmark. ${ }^{195}$ It is important to mention that the factors associated with the increased development of resistance in C. glabrata isolates remain unknown. ${ }^{195}$

In Latin America, a single case report has demonstrated clinical and microbiological echinocandin resistance in Candida. Bizerra et al. [196], using sequencing methodologies for the study of FKS genes and quantification of glucan synthesis, reported the occurrence of a mutation associated with this resistance phenotype in C. glabrata isolated from a single patient.

To date, little is known about echinocandin resistance in Aspergillus, particularly because susceptibility tests are not performed routinely and present technical difficulties and problems associated with reproducibility and the clinical-in vitro testing correlation. ${ }^{197,198}$
Because the therapeutic outcome of treatment of aspergillosis with echinocandins is poorer than with polyenes and triazoles, the use of echinocandins in these patients is limited and restricted to cases involving empirical or combination therapies. ${ }^{189,198,199}$ Consequently, few cases of secondary resistance of Aspergillus to this therapeutic class have been reported. However, non-Aspergillus fumigatus species may exhibit primary resistance, as is the case in A. lentulus. ${ }^{200,201}$

\section{Molecular mechanisms of echinocandin resistance in Candida spp. and Aspergillus spp.}

Echinocandins present predominantly fungicidal activity against Candida spp. and fungistatic activity against Aspergillus spp. ${ }^{202-204}$

Experimental data have shown that the primary mechanism of action of echinocandins is associated with inhibition of the synthesis of the fungal cell wall via inhibition of $\beta$-1,3-glucan synthase (Fks1/AfFks1 for Aspergillus fumigatus), which is responsible for the synthesis of $\beta-1,3$-glucans. ${ }^{205}$ In fungi belonging to the phylum Ascomycota, the paralogous genes FKS1, FKS2 2 and FKS3 are responsible for the synthesis of $\beta$ 1,3-glucan synthase. In most species, the FKS1 gene is more active, whereas FKS2 is expressed in adverse conditions and only during the sexual cycle and sporulation. ${ }^{205}$ The FKS3 gene is involved in the formation of the cell walls of spores. ${ }^{206}$ In some species, including C. glabrata, FKS1 and FKS2 are functionally redundant. ${ }^{207}$ In Aspergillus spp., only FKS1 has been described. ${ }^{208}$ The echinocandin resistance mechanisms reported in Candida spp. and Aspergillus spp. will be discussed below.

\section{Mutations in the FKS genes}

The main resistance mechanism described for echinocandins involves the occurrence of mutations in the FKS1 gene, resulting in conformational changes in the enzyme encoded by this gene (Fks1), decreased affinity between echinocandins and Fks1, and the consequent resistance to these compounds. ${ }^{209-212}$ These mutations occur in two specific, highly conserved regions of the FKS1 gene known as hot spot 1 (HS1), corresponding to positions 641-649 in the amino acid sequence of the Fks1 protein, and hot spot 2 (HS2), spanning positions 1345-1365 of the amino acid sequence. $^{211,213}$

In C. albicans, among the mutations already described, the replacement of serine with proline, 
phenylalanine or tyrosine at position 645 has been described as the most frequent event. ${ }^{14,211,213-215}$ In fact, Balashov et al. [209] found that, among 85 caspofungin-resistant isolates of C. albicans, $93 \%$ had a mutation in the serine residue at position 645 .

Mutations in FKS1 have been described not only in C. albicans but also in C. krusei, C. parapsilosis and C. tropicalis and, more recently, in C. kefyr. ${ }^{201,210,213,214,216,217}$ In C. glabrata, in addition to mutations in FKS1, mutations in the FKS2 gene have been associated with echinocandin resistance. ${ }^{196,218-221}$

In contrast to the mutations described for the Candida species that develop secondary resistance to echinocandins, isolates of the complexes C. guilliermondii and $C$. parapsilosis develop natural mutations, not due to exposure to the drug, which explain their higher MIC values to all echinocandins. ${ }^{222-224}$ In fact, the Fks1 coding regions of all members of the C. parapsilosis complex contain a mutation at position 660 of the amino acid sequence involving the substitution of proline with alanine. ${ }^{216}$ Similarly, it has been reported that the Fks1 coding regions of all isolates of C. guilliermondii contain a substitution at position 642 of the amino acid sequence. ${ }^{211}$ Despite the higher MIC values, various experimental and clinical studies have demonstrated that these drugs exhibit inhibitory activity against C. parapsilosis infections. However, their antifungal activity is only fungistatic and not fungicidal, which may explain the higher incidence of persistent candidaemia with $C$. parapsilosis in patients treated with echinocandins. ${ }^{25-229}$

Despite the advances made in the characterisation of echinocandin resistance mechanisms in Candida, to date, little is known about the molecular basis of Aspergillus resistance to these drugs. ${ }^{56}$ Moreover, few clinical isolates associated with treatment failure have been investigated. Arendrup et al. [230] evaluated the echinocandin resistance mechanism of an isolate of A. fumigatus isolated from a patient with invasive pulmonary aspergillosis who experienced treatment failure with caspofungin; this isolate did not harbour mutations in the AfFKS1 gene; therefore, the $\beta$-1,3-glucan synthase was completely sensitive in vitro. However, the AfFKS1 gene was overexpressed, indicating that treatment with caspofungin did not decrease the expression of this gene. Similarly, Arendrup et al. [231] studied the amplified DNA of A. fumigatus from liver and lung tissue samples from a patient with aspergillosis subjected to long-term therapy with caspofungin, but did not find any mutations in the sequence of the hot spot region of AfFKS1.
Because the reports of echinocandin resistance in clinical isolates are rare, several researchers have sought in vitro models for the induction of resistance in the laboratory with the aim of better characterising the resistance mechanisms associated with these drugs. Gardiner et al. [232] inserted a site-directed mutation in AfKS1 consisting of a substitution of serine with tyrosine at codon 678 (S678Y). This mutation decreased the susceptibility to caspofungin 16-fold, with a minimum effective concentration (MEC) of $4 \mu \mathrm{g} / \mathrm{mL}$. This same study used mini-array analysis of 220 target genes to evaluate the expression of relevant genes that could contribute to the decrease in the susceptibility to caspofungin in mutant isolates. Their results allowed the identification of (i) increased expression levels of 28 genes encoding structural components of the cell wall (AGS2, CWP1, MCI36), (ii) enzymes responsible for cell wall biosynthesis (Krel, Mci35) and (iii) signal transducers (MAPK, MCI106). The expression levels of genes encoding proteins involved in transportation, such as MDR1 and MDR4, were also increased in this mutant. ${ }^{232}$

Rocha et al. [233] generated a mutant by the substitution of serine with proline at codon 678 (S678P) in AfKS1, and this change was sufficient to confer resistance to three echinocandins, demonstrating that the modification in Fks1 is a conserved mechanism in echinocandin resistance among pathogenic fungi.

Of note are the differences in the in vitro susceptibility profile to echinocandins between different species of Aspergillus. For example A. niger exhibited higher MECs to echinocandins compared with other species, suggesting the occurrence of differences in the cell wall composition in these fungal species. ${ }^{234}$ In contrast, $A$. lentulus was less susceptible to caspofungin, although it was apparently susceptible to micafungin and anidulafungin. The analysis of the FKS1 region of this fungal species indicated no polymorphism in the hot spot region of this gene. ${ }^{56,197}$ One hypothesis to explain this phenomenon is the excessive production of glucan by this species, which could limit the effective concentrations of antifungal agents. ${ }^{208}$

\section{Increase in chitin synthesis}

The increase in chitin synthesis has been described as an important resistance mechanism against echinocandins. Walker et al. [235] have shown that the exposure of $C$. albicans to low levels of echinocandins induces the expression of genes encoding chitin synthases, increases the concentration of chitin in the cell wall and consequently decreases the activity of 
echinocandin. Corroborating this hypothesis, Plaine et al. [236] demonstrated that C. albicans mutants with higher levels of chitin in the cell wall were resistant to caspofungin, whereas those with decreased levels of chitin were very susceptible to this drug.

Increased chitin concentrations after exposure to echinocandins have also been reported in C. glabrata, C. guilliermondii, C. krusei, C. parapsilosis and C. tropicalis. ${ }^{23,238}$

\section{Risk factors for the development of candidaemia with echinocandin-resistant isolates}

Although still rare, cases of echinocandin resistance in clinical isolates of Candida have been increasingly reported, in particular among C. glabrata isolates. ${ }^{193}$

Using case-control studies, several authors have highlighted that prior exposure to echinocandins results in a higher risk of developing candidaemia due to the lower susceptibility of these isolates to this class of antifungal agents. ${ }^{215,239,240}$ For infections due to $C$. glabrata, in addition to the previous exposure to antifungal agents, exposure to total parenteral nutrition (TPN) has also been reported to be a predisposing factor. ${ }^{241-243}$ Recent studies have indicated the development of echinocandin resistance after short periods of exposure to these antifungal agents. In fact, Ruggero and Topal identified a C. albicans isolate with a FKS1 mutation after 14 days of prophylactic therapy with micafungin. ${ }^{244}$

\section{Resistance to amphotericin B}

Amphotericin $\mathrm{B}$ is an antifungal agent belonging to the class of polyenes which are natural antifungal compounds produced by species of the genus Streptomyces. Since the 1950s until the discovery of azoles, standard therapy for IFIs involved the use of amphotericin B. Because of its broad spectrum of activity against yeasts, filamentous and dimorphic fungi and its fungicidal activity, amphotericin B based drugs are still considered the gold standard for the treatment of most fungal infections, particularly in cases of severe IFI, when a quick response is required. ${ }^{89,200,245-247}$

The classical mechanism of action of amphotericin $\mathrm{B}$ involves the irreversible binding to ergosterol present in the plasma membranes of fungal cells, resulting in the formation of pores in the cell membrane, with loss of $\mathrm{K}^{+}$and $\mathrm{Na}^{+}$ions, which leads to impairment of the cellular osmotic balance and consequent cell death. $^{89,248,249}$ Furthermore, recent findings have shown that exposure to amphotericin B induces the production and accumulation of reactive oxygen species, which eventually causes cell death. ${ }^{250,251}$

Although amphotericin B has a broad spectrum of activity, this antifungal drug is highly toxic to the host. Nephrotoxicity is the major side-effect, which has limited its clinical use. ${ }^{188,252-256}$ To decrease drug toxicity, lipid formulations have been developed which are currently first choice of treatment of IFIs. ${ }^{257-261}$

Secondary resistance to amphotericin B is rare among isolates of Candida spp., but some cases of resistance have been reported. ${ }^{135,262-267}$ Several studies have shown resistance of $C$. Iusitaniae to this drug. Although these studies reported that $C$. lusitaniae isolates have low rates of resistance in vitro, this species seems to develop secondary resistance during treatment with amphotericin $\mathrm{B}$, and several cases of therapeutic failure are on record. ${ }^{267-274}$

Similar to Candida, secondary resistance to amphotericin B has not been observed in Aspergillus, although some patients experienced treatment failure when using this drug. ${ }^{262,263,275}$ However, primary resistance to amphotericin $B$ has been reported among isolates of A. flavus, A. lentulus, A. terreus and A. ustus. ${ }^{48,53,276-280}$

Previous studies have also shown that isolates of $A$. flavus exhibit higher MIC values to amphotericin B compared with isolates belonging to the section Fumigati. $^{65,199,276,277,279,281}$

Hadrich et al. [277] evaluated the in vitro susceptibility to amphotericin B of $37 \mathrm{~A}$. flavus isolates recovered from 14 patients with haematological malignancies, of which 13 were treated with amphotericin B deoxycholate. Of the total isolates evaluated, $84 \% \quad(N=31)$ exhibited resistance to this drug in vitro. Among the patients infected with resistant isolates, nine were treated with amphotericin $\mathrm{B}$, and $88 \%$ $(N=7)$ died. ${ }^{277}$ Similar results were observed by LassFlörl et al. [281], who compared the in vitro susceptibility to amphotericin B in strains of A. flavus with clinical outcome of patients undergoing bone narrow transplantation. In this study, 12 A. flavus sensu lato isolates were evaluated. Only patients infected with susceptible isolates (MIC to AMB $<2 \mu \mathrm{g} / \mathrm{mL}, N=4$ ) survived, whereas those infected with resistant isolates (CIM to $\mathrm{AMB} \geq 2 \mu \mathrm{g} / \mathrm{mL}, N=8$ ) died. ${ }^{281}$

Alastruey-Izquierdo et al. [65] evaluated 280 clinical isolates of Aspergillus from 29 Spanish hospitals and reported a rate of resistance to amphotericin B of $10.8 \%$. In this series, four of $27(14.8 \%)$ A. flavus isolates and seven of $26(27 \%)$ A. terreus isolates were resistant to this drug. In Brazil, Gonçalves et al. [54] 
observed a high rate of resistance $(49 \%)$ to amphotericin $\mathrm{B}$ in a series consisting of 77 clinical isolates belonging to the section Flavi. Likewise studies from India show high amphotericin B MICs in 31 out of 37 isolates (84\%) [277]. However, the genetic mechanisms responsible for acquired resistance to amphotericin B have not been elucidated. Some studies have indicated that mutations in the genes involved in the biosynthetic pathway of ergosterol (ERG), including ERG2, ERG3, ERG5, ERG6 and ERG11, may lead to decreased concentration of ergosterol and the formation of intermediate sterols in the fungal cell membrane. ${ }^{104,282-286}$ These quantitative and qualitative changes in plasma membrane sterols decrease the affinity of amphotericin B for its target sites and constitute the major mechanisms of resistance of Candida isolates to this drug.

Although most of the data related to resistance mechanisms for amphotericin B have been observed in trials with yeast, Chamilos and Kontoyiannis thoroughly reviewed these mechanisms in Aspergillus. These authors reported that these mechanisms can be attributed to two phenomena: (i) a decreased concentration of membrane ergosterol via mutations in the biosynthetic pathway of ergosterol and/or prior exposure to triazoles, and (ii) increased production of reducing enzymes (e.g. catalase), which confer resistance to oxidative stress and can also act as oxidising agents. ${ }^{287}$

Although A. terreus is the best studied species, its intrinsic mechanism of resistance to amphotericin B is not fully elucidated but has been attributed to the high expression levels of catalase, an enzyme that causes damage to the fungal cell membrane via generation of reactive oxygen species. ${ }^{288} \mathrm{~A}$ recent study showed that application of pro-oxidants significantly affects amphotericin B efficacy by rendering resistant isolates more susceptible to this drug which was also confirmed in vivo in a Galleria model. ${ }^{289}$

\section{Conclusions}

Over the past few years, the significant increase in the use of antifungal agents for the treatment of candidiasis and invasive aspergillosis has resulted in the emergence of resistant clinical isolates, particularly against triazoles and echinocandins. In addition, a recent emergence of fluconazole resistance among isolates that were primarily sensitive to this drug, including $C$. parapsilosis and $C$. tropicalis has been noted. For echinocandins, despite the low resistance rates, the occurrence of isolates with lower susceptibility to this drug has been increasingly reported, particularly among C. glabrata isolates.

Therefore, we highlight the need to conduct antifungal resistance surveillance studies using clinical isolates of Candida and Aspergillus in different geographical regions and monitoring of the infection rates in distinct population groups with the aims of early detection of resistance to these drugs and implementation of efficient policies for infection control and treatment.

\section{Acknowledgments}

This study was supported by the Fundação de Amparo a Pesquisa do Estado de São Paulo (FAPESP) (2012/ 04767-1) and Conselho Nacional de Desenvolvimento Científico e Tecnológico (CNPq), Brazil, (308011/ 2010-4). S.S.G. received a postdoctoral fellowship from the Coordenação de Aperfeiçoamento de Pessoal de Nível Superior (CAPES), Brazil (PNPD 23038.007393/ 2011-11). A.C.R.S. received a doctoral fellowship from FAPESP (2012/04769-4). A.L.C. received grants from FAPESP and CNPq.

\section{Potential conflicts of interest}

A.L.C. has received educational funds from Pfizer and Gilead, funding for research from Pfizer and United Medical and funds for advisory board membership from MSD and United Medical. J.F.M. received grants from Astellas, Basilea and Merck. He has been a consultant to Astellas, Basilea and Merck and received speaker's fees from Merck, United Medical and Gilead. All other authors: none to declare.

\section{References}

1 Magill SS, Edwards JR, Bamberg W et al. Multistate point-prevalence survey of health care-associated infections. $N$ Engl J Med 2014; 370: 1198-208.

2 Garey KW, Aitken SL, Dima-Ala A et al. Echinocandin use in hospitalized patients: a multi-institutional study. Am J Med Sci 2015; 349: $316-20$.

3 Meersseman W, Lagrou K, Maertens J, Van Wijngaerden E. Invasive aspergillosis in the intensive care unit. Clin Infect Dis 2007; 45: 205-16.

4 Arendrup MC, Dzajic E, Jensen RH et al. Epidemiological changes with potential implication for antifungal prescription recommendations for fungaemia: data from a nationwide fungaemia surveillance programme. Clin Microbiol Infect 2013; 19: E343-53.

5 Nucci M, Queiroz-Telles F, Tobon AM, Restrepo A, Colombo AL. Epidemiology of opportunistic fungal infections in Latin America. Clin Infect Dis 2010; 51: 561-70.

6 Fraczek MG, Kirwan MB, Moore CB, Morris J, Denning DW, Richardson MD. Volume dependency for culture of fungi from 
respiratory secretions and increased sensitivity of Aspergillus quantitative PCR. Mycoses 2014; 57: 69-78.

7 Allou N, Allyn J, Montravers P. When and how to cover for fungal infections in patients with severe sepsis and septic shock. Curr Infect Dis Rep 2011; 13: 426-32.

8 Bow EJ, Vanness DJ, Slavin M et al. Systematic review and mixed treatment comparison meta-analysis of randomized clinical trials of primary oral antifungal prophylaxis in allogeneic hematopoietic cell transplant recipients. BMC Infect Dis 2015; 15: 128.

9 Candoni A, Caira M, Cesaro S et al. Multicentre surveillance study on feasibility, safety and efficacy of antifungal combination therapy for proven or probable invasive fungal diseases in haematological patients: the SEIFEM real-life combo study. Mycoses 2014; 57: 342-50.

10 Apisarnthanarak A, Yatrasert A, Mundy LM. Impact of education and an antifungal stewardship program for candidiasis at a Thai tertiary care center. Infect Control Hosp Epidemiol 2010; 31: 722-7.

11 Valerio M, Munoz P, Rodriguez-Gonzalez C et al. Training should be the first step toward an antifungal stewardship program. Enferm Infecc Microbiol Clin 2015; 33: 221-7.

12 Verweij PE, Chowdhary A, Melchers WJ, Meis JF. Azole resistance in Aspergillus fumigatus: Can we retain the clinical use of moldactive antifungal azoles? Clin Infect Dis 2015; 2016(62): 362-8. pii: civ885. [Epub ahead of print].

13 Sanguinetti M, Posteraro B, Lass-Florl C. Antifungal drug resistance among Candida species: mechanisms and clinical impact. Mycoses 2015; 58(Suppl 2): 2-13.

14 Cowen LE, Sanglard D, Howard SJ, Rogers PD, Perlin DS. Mechanisms of antifungal drug resistance. Cold Spring Harb Perspect Med 2015; 5: a019752.

15 Das I, Nightingale P, Patel M, Jumaa P. Epidemiology, clinical characteristics, and outcome of candidemia: experience in a tertiary referral center in the UK. Int J Infect Dis 2011; 15: e759-63.

16 Arendrup MC, Bruun B, Christensen JJ et al. National surveillance of fungemia in Denmark (2004 to 2009). J Clin Microbiol 2011; 49: $325-34$

17 Peman J, Canton E, Minana JJ et al. [Changes in the epidemiology of fungaemia and fluconazole susceptibility of blood isolates during the last 10 years in Spain: results from the FUNGEMYCA study]. Rev Iberoam Micol 2011; 28: 91-9.

18 Tragiannidis A, Fegeler W, Rellensmann G et al. Candidaemia in a European Paediatric University Hospital: a 10-year observational study. Clin Microbiol Infect 2012; 18: E27-30.

19 Cleveland AA, Farley MM, Harrison LH et al. Changes in incidence and antifungal drug resistance in candidemia: results from population-based laboratory surveillance in Atlanta and Baltimore, 20082011. Clin Infect Dis 2012; 55: 1352-61.

20 Lockhart SR, Iqbal N, Cleveland AA et al. Species identification and antifungal susceptibility testing of Candida bloodstream isolates from population-based surveillance studies in two U.S. cities from 2008 to 2011. J Clin Microbiol 2012; 50: 3435-42.

21 Asmundsdottir LR, Erlendsdottir H, Gottfredsson M. Nationwide study of candidemia, antifungal use, and antifungal drug resistance in Iceland, 2000 to 2011. J Clin Microbiol 2013; 51: 841-8.

22 Ericsson J, Chryssanthou E, Klingspor L et al. Candidaemia in Sweden: a nationwide prospective observational survey. Clin Microbiol Infect 2013; 19: E218-21.

23 Klingspor L, Tortorano AM, Peman J et al. Invasive Candida infections in surgical patients in intensive care units: a prospective, multicentre survey initiated by the European Confederation of Medical Mycology (ECMM) (2006-2008). Clin Microbiol Infect 2015 21: e1-10.

24 Puig-Asensio M, Padilla B, Garnacho-Montero J et al. Epidemiology and predictive factors for early and late mortality in Candida bloodstream infections: a population-based surveillance in Spain. Clin Microbiol Infect 2014; 20: 0245-54.

25 Pfaller MA, Jones RN, Castanheira M. Regional data analysis of Candida non-albicans strains collected in United States medical sites over a 6-year period, 2006-2011. Mycoses 2014; 57: 602-11.
26 Pfaller MA, Andes DR, Diekema DJ et al. Epidemiology and outcomes of invasive candidiasis due to non-albicans species of Candida in 2,496 patients: data from the Prospective Antifungal Therapy (PATH) registry 2004-2008. PLoS ONE 2014; 9: e101510

27 Guinea J, Zaragoza O, Escribano P et al. Molecular identification and antifungal susceptibility of yeast isolates causing fungemia collected in a population-based study in Spain in 2010 and 2011. Antimicrob Agents Chemother 2014; 58: 1529-37.

28 Moretti ML, Trabasso P, Lyra L et al. Is the incidence of candidemia caused by Candida glabrata increasing in Brazil? Five-year surveillance of Candida bloodstream infection in a university reference hospital in southeast Brazil. Med Mycol 2013; 51: 225-30.

29 Colombo AL, Garnica M, Aranha Camargo LF et al. Candida glabrata: an emerging pathogen in Brazilian tertiary care hospitals. Med Mycol 2013; 51: 38-44.

30 Colombo AL, Guimaraes T, Sukienik T et al. Prognostic factors and historical trends in the epidemiology of candidemia in critically ill patients: an analysis of five multicenter studies sequentially conducted over a 9-year period. Intensive Care Med 2014; 40: 1489-98.

31 Omrani AS, Makkawy EA, Baig K et al. Ten-year review of invasive Candida infections ina tertiary care center in Saudi Arabia. Saudi Med J 2014; 35: 821-6.

32 Tan BH, Chakrabarti A, Li RY et al. Incidence and species distribution of candidaemia in Asia: a laboratory-based surveillance study. Clin Microbiol Infect 2015; 21: 946-53.

33 Cheng YR, Lin LC, Young TG, Liu CE, Chen CH, Tsay RW. Risk factors for candidemia-related mortality at a medical center in central Taiwan. J Microbiol Immunol Infect 2006; 39: 155-61.

34 Chowdhary A, Becker K, Fegeler W et al. An outbreak of candidemia due to Candida tropicalis in a neonatal intensive care unit. Mycoses 2003; 46: 287-92.

35 Kothavade RJ, Kura MM, Valand AG, Panthaki MH. Candida tropicalis: its prevalence, pathogenicity and increasing resistance to fluconazole. J Med Microbiol 2010; 59: 873-80.

36 Taj-Aldeen SJ, Kolecka A, Boesten R et al. Epidemiology of candidemia in Qatar, the Middle East: performance of MALDI-TOF MS for the identification of Candida species, species distribution, outcome, and susceptibility pattern. Infection 2014; 42: 393-404.

37 Ellis M, Hedstrom U, Jumaa P, Bener A. Epidemiology, presentation, management and outcome of candidemia in a tertiary care teaching hospital in the United Arab Emirates, 1995-2001. Med Mycol 2003; 41: 521-8.

38 Chowdhary A, Sharma C, Duggal S et al. New clonal strain of Candida auris, Delhi. India. Emerg Infect Dis 2013; 19: 1670-3.

39 Chowdhary A, Anil Kumar V, Sharma C et al. Multidrug-resistant endemic clonal strain of Candida auris in India. Eur J Clin Microbiol Infect Dis 2014; 33: 919-26.

40 Kathuria S, Singh PK, Sharma C et al. Multidrug-resistant Candida auris misidentified as Candida haemulonii: Characterization by Matrix-Assisted Laser Desorption Ionization-Time of Flight Mass Spectrometry and DNA sequencing and its antifungal susceptibility profile variability by Vitek 2, CLSI broth microdilution, and Etest method. J Clin Microbiol 2015; 53: 1823-30.

41 Sharma C, Kumar N, Meis JF, Pandey R, Chowdhary A. Draft genome sequence of a fluconazole-resistant Candida auris strain from a candidemia patient in India. Genome Announc 2015; pii: e0072215. doi: 10.1128/genomeA.00722-15.

42 Jung DS, Farmakiotis D, Jiang Y, Tarrand JJ, Kontoyiannis DP. Uncommon Candida species fungemia among cancer patients, Houston, Texas. USA. Emerg Infect Dis 2015; 21: 1942-50.

43 Minea B, Nastasa V, Moraru RF et al. Species distribution and susceptibility profile to fluconazole, voriconazole and MXP-4509 of 551 clinical yeast isolates from a Romanian multi-centre study. Eur J Clin Microbiol Infect Dis 2015; 34: 367-83.

44 Pinhati HM, Bizerra FC, Siqueira RA, Castro FF, Colombo AL. Outbreak of candidemia due fluconazole resistant Candida parapsilosis strains in a tertiary care hospital in Brazil. Fifty-third Interscience Conference 
on Antimicrobial Agents and Chemotherapy. American Society for Microbiology: Denver, CO, 2013.

45 Souza AC, Fuchs BB, Pinhati HM et al. Candida parapsilosis resistance to fluconazole: Molecular mechanisms and in vivo impact in infected Galleria mellonella larvae. Antimicrob Agents Chemother 2015; 59: 6581-7.

46 Verweij PE, Snelders E, Kema GH, Mellado E, Melchers WJ. Azole resistance in Aspergillus fumigatus: a side-effect of environmental fungicide use? Lancet Infect Dis 2009; 9: 789-95.

47 van der Linden JW, Snelders E, Arends JP, Daenen SM, Melchers WJ, Verweij PE. Rapid diagnosis of azole-resistant aspergillosis by direct PCR using tissue specimens. J Clin Microbiol 2010; 48: 1478-80.

48 Balajee SA, Gribskov JL, Hanley E, Nickle D, Marr KA. Aspergillus lentulus sp. nov., a new sibling species of A. fumigatus. Eukaryot Cell 2005; 4: 625-32.

49 Alcazar-Fuoli L, Mellado E, Alastruey-Izquierdo A, Cuenca-Estrella M, Rodriguez-Tudela JL. Aspergillus section Fumigati: antifungal susceptibility patterns and sequence-based identification. Antimicrob Agents Chemother 2008; 52: 1244-51.

50 Bastos VR, Santos DW, Padovan AC et al. Early invasive pulmonary aspergillosis in a kidney transplant recipient caused by Aspergillus lentulus: first Brazilian report. Mycopathologia 2015; 179: 299-305.

51 Barchiesi F, Mazzocato S, Mazzanti S et al. Invasive aspergillosis in liver transplant recipients: epidemiology, clinical characteristics, treatment, and outcomes in 116 cases. Liver Transpl 2015; 21 : 204-12.

52 Kathuria S, Sharma C, Singh PK et al. Molecular epidemiology and in-vitro antifungal susceptibility of Aspergillus terreus species complex isolates in Delhi, India: evidence of genetic diversity by amplified fragment length polymorphism and microsatellite typing. PLoS ONE 2015; 10: e0118997.

53 Azzola A, Passweg JR, Habicht JM et al. Use of lung resection and voriconazole for successful treatment of invasive pulmonary Aspergillus ustus infection. J Clin Microbiol 2004; 42: 4805-8.

54 Goncalves SS, Stchigel AM, Cano J, Guarro J, Colombo AL. In vitro antifungal susceptibility of clinically relevant species belonging to Aspergillus section Flavi. Antimicrob Agents Chemother 2013; 57: 1944-7.

55 Shivaprakash MR, Geertsen E, Chakrabarti A, Mouton JW, Meis JF. In vitro susceptibility of 188 clinical and environmental isolates of Aspergillus flavus for the new triazole isavuconazole and seven other antifungal drugs. Mycoses 2011; 54: e583-9.

56 Howard SJ, Arendrup MC. Acquired antifungal drug resistance in Aspergillus fumigatus: epidemiology and detection. Med Mycol 2011; 49(Suppl 1): S90-5.

57 Chowdhary A, Kathuria S, Xu J, Meis JF. Emergence of azole-resistant Aspergillus fumigatus strains due to agricultural azole use creates an increasing threat to human health. PLoS Pathog 2013; 9: e1003633.

58 Paul RA, Rudramurthy SM, Meis JF, Mouton JW, Chakrabarti A. A novel Y319H substitution in Cyp51C associated with azole resistance in Aspergillus flavus. Antimicrob Agents Chemother 2015; 59: 6615-9.

59 Arendrup MC, Jensen RH, Grif K et al. In vivo emergence of Aspergillus terreus with reduced azole susceptibility and a Cyp51A M217I alteration. J Infect Dis 2012; 206: 981-5.

60 Pfaller MA, Messer SA, Boyken L et al. In vitro survey of triazole cross-resistance among more than 700 clinical isolates of Aspergillus species. J Clin Microbiol 2008; 46: 2568-72.

61 Pham CD, Reiss E, Hagen F, Meis JF, Lockhart SR. Passive surveillance for azole-resistant Aspergillus fumigatus, United States, 20112013. Emerg Infect Dis 2014; 20: 1498-503.

62 Denning DW, Pleuvry A, Cole DC. Global burden of chronic pulmonary aspergillosis as a sequel to pulmonary tuberculosis. Bull World Health Organ 2011; 89: 864-72.

63 Mellado E, Garcia-Effron G, Alcazar-Fuoli L et al. A new Aspergillus fumigatus resistance mechanism conferring in vitro cross-resistance to azole antifungals involves a combination of cyp $51 \mathrm{~A}$ alterations. Antimicrob Agents Chemother 2007; 51: 1897-904.

64 Fischer J, van Koningsbruggen-Rietschel S, Rietschel E et al. Prevalence and molecular characterization of azole resistance in Aspergillus spp. isolates from German cystic fibrosis patients. J Antimicrob Chemother 2014; 69: 1533-6.

65 Alastruey-Izquierdo A, Mellado E, Pelaez T et al. Population-based survey of filamentous fungi and antifungal resistance in Spain (FILPOP Study). Antimicrob Agents Chemother 2013; 57: 3380-7.

66 Baddley JW, Marr KA, Andes DR et al. Patterns of susceptibility of Aspergillus isolates recovered from patients enrolled in the Transplant-Associated Infection Surveillance Network. J Clin Microbiol 2009; 47: 3271-5.

67 Snelders E, van der Lee HA, Kuijpers J et al. Emergence of azole resistance in Aspergillus fumigatus and spread of a single resistance mechanism. PLoS Med 2008; 5: e219.

68 Howard SJ, Cerar D, Anderson MJ et al. Frequency and evolution of azole resistance in Aspergillus fumigatus associated with treatment failure. Emerg Infect Dis 2009; 15: 1068-76.

69 Bueid A, Howard SJ, Moore CB et al. Azole antifungal resistance in Aspergillus fumigatus: 2008 and 2009. J Antimicrob Chemother 2010; 65: $2116-8$.

70 Schweer KE, Bangard C, Hekmat K, Cornely OA. Chronic pulmonary aspergillosis. Mycoses 2014; 57: 257-70.

71 Verweij PE, Te Dorsthorst DT, Rijs AJ, De Vries-Hospers HG, Meis JF. Nationwide survey of in vitro activities of itraconazole and voriconazole against clinical Aspergillus fumigatus isolates cultured between 1945 and 1998. J Clin Microbiol 2002; 40: 2648-50.

72 van der Linden JW, Snelders E, Kampinga GA et al. Clinical implications of azole resistance in Aspergillus fumigatus, The Netherlands, 2007-2009. Emerg Infect Dis 2011; 17: 1846-54.

73 van der Linden JW, Camps SM, Kampinga GA et al. Aspergillosis due to voriconazole highly resistant Aspergillus fumigatus and recovery of genetically related resistant isolates from domiciles. Clin Infect Dis 2013; 57: 513-20.

74 van Ingen J, van der Lee HA, Rijs TA et al. Azole, polyene and echinocandin MIC distributions for wild-type, TR34/L98H and TR46/Y121F/T289A Aspergillus fumigatus isolates in the Netherlands. J Antimicrob Chemother 2015; 70: 178-81.

75 Fuhren J, Voskuil WS, Boel CH et al. High prevalence of azole resistance in Aspergillus fumigatus isolates from high-risk patients. $J$ Antimicrob Chemother 2015; 70: 2894-8.

76 Tashiro M, Izumikawa K, Hirano K et al. Correlation between triazole treatment history and susceptibility in clinically isolated Aspergillus fumigatus. Antimicrob Agents Chemother 2012; 56: 4870-5.

77 Negri CE, Goncalves SS, Xafranski H et al. Cryptic and rare Aspergillus species in Brazil: prevalence in clinical samples and in vitro susceptibility to triazoles. J Clin Microbiol 2014; 52: 3633-40.

78 Chowdhary A, Kathuria S, Randhawa HS, Gaur SN, Klaassen CH, Meis JF. Isolation of multiple-triazole-resistant Aspergillus fumigatus strains carrying the TR/L98H mutations in the cyp51A gene in India. J Antimicrob Chemother 2012; 67: 362-6.

79 Chowdhary A, Kathuria S, Xu J et al. Clonal expansion and emergence of environmental multiple-triazole-resistant Aspergillus fumigatus strains carrying the $\mathrm{TR}_{34} / \mathrm{L} 98 \mathrm{H}$ mutations in the cyp $51 \mathrm{~A}$ gene in India. PLoS ONE 2012; 7: e52871.

80 Chowdhary A, Sharma C, Kathuria S, Hagen F, Meis JF. Prevalence and mechanism of triazole resistance in Aspergillus fumigatus in a referral chest hospital in Delhi, India and an update of the situation in Asia. Front Microbiol 2015; 6: 428.

81 Lockhart SR, Frade JP, Etienne KA, Pfaller MA, Diekema DJ, Balajee SA. Azole resistance in Aspergillus fumigatus isolates from the ARTEMIS global surveillance study is primarily due to the TR/L98H mutation in the cyp51A gene. Antimicrob Agents Chemother 2011; 55: $4465-8$.

82 Tashiro M, Izumikawa K, Minematsu A et al. Antifungal susceptibilities of Aspergillus fumigatus clinical isolates obtained in Nagasaki. Japan. Antimicrob Agents Chemother 2012; 56: 584-7. 
83 Seyedmousavi S, Hashemi SJ, Zibafar E et al. Azole-resistant Aspergillus fumigatus. Iran. Emerg Infect Dis 2013; 19: 832-4.

84 Ahmad S, Joseph L, Hagen F, Meis JF, Khan Z. Concomitant occurrence of itraconazole-resistant and -susceptible strains of Aspergillus fumigatus in routine cultures. J Antimicrob Chemother 2015; 70: $412-5$.

85 Vanden Bossche H. Biochemical targets for antifungal azole derivatives: hypothesis on the mode of action. Curr Top Med Mycol 1985; 1: $313-51$.

86 Chen SC, Sorrell TC, Chang CC, Paige EK, Bryant PA, Slavin MA. Consensus guidelines for the treatment of yeast infections in the haematology, oncology and intensive care setting, 2014. Intern Med J 2014; 44: 1315-32.

87 Parker JE, Warrilow AG, Price CL, Mullins JG, Kelly DE, Kelly SL. Resistance to antifungals that target CYP51. J Chem Biol 2014; 7: 143-61.

88 Sanglard D, Ischer F, Monod M, Bille J. Cloning of Candida albicans genes conferring resistance to azole antifungal agents: characterization of CDR2, a new multidrug ABC transporter gene. Microbiology 1997; 143: 405-16.

89 Sanglard D, Coste A, Ferrari S. Antifungal drug resistance mechanisms in fungal pathogens from the perspective of transcriptional gene regulation. FEMS Yeast Res 2009; 9: 1029-50.

90 Sanglard D, Ischer F, Monod M, Bille J. Susceptibilities of Candida albicans multidrug transporter mutants to various antifungal agents and other metabolic inhibitors. Antimicrob Agents Chemother 1996; 40: $2300-5$.

91 Sanglard D, Kuchler K, Ischer F, Pagani JL, Monod M, Bille J. Mechanisms of resistance to azole antifungal agents in Candida albicans isolates from AIDS patients involve specific multidrug transporters. Antimicrob Agents Chemother 1995; 39: 2378-86.

92 White TC. Increased mRNA levels of ERG16, CDR, and MDR1 correlate with increases in azole resistance in Candida albicans isolates from a patient infected with human immunodeficiency virus. Antimicrob Agents Chemother 1997; 41: 1482-7.

93 Goldman GH, da Silva Ferreira ME, dos Reis Marques E et al. Evaluation of fluconazole resistance mechanisms in Candida albicans clinical isolates from HIV-infected patients in Brazil. Diagn Microbiol Infect Dis 2004; 50: 25-32.

$94 \mathrm{Hu}$ L, Du X, Li T et al. Genetic and phenotypic characterization of Candida albicans strains isolated from infectious disease patients in Shanghai. J Med Microbiol 2015; 64: 74-83.

95 Moran GP, Sanglard D, Donnelly SM, Shanley DB, Sullivan DJ, Coleman DC. Identification and expression of multidrug transporters responsible for fluconazole resistance in Candida dubliniensis. Antimicrob Agents Chemother 1998; 42: 1819-30.

96 Sanglard D, Ischer F, Bille J. Role of ATP-binding-cassette transporter genes in high-frequency acquisition of resistance to azole antifungals in Candida glabrata. Antimicrob Agents Chemother 2001; 45: $1174-83$.

97 Sanglard D, Ischer F, Calabrese D, Majcherczyk PA, Bille J. The ATP binding cassette transporter gene CgCDR1 from Candida glabrata is involved in the resistance of clinical isolates to azole antifungal agents. Antimicrob Agents Chemother 1999; 43: 2753-65.

98 Katiyar SK, Edlind TD. Identification and expression of multidrug resistance-related $\mathrm{ABC}$ transporter genes in Candida krusei. Med Mycol 2001; 39: 109-16.

99 Pinjon E, Moran GP, Jackson CJ et al. Molecular mechanisms of itraconazole resistance in Candida dubliniensis. Antimicrob Agents Chemother 2003; 47: 2424-37.

100 Torelli R, Posteraro B, Ferrari S et al. The ATP-binding cassette transporter-encoding gene CgSNQ2 is contributing to the CgPDR1dependent azole resistance of Candida glabrata. Mol Microbiol 2008; 68: $186-201$.

101 Caudle KE, Barker KS, Wiederhold NP, Xu L, Homayouni R, Rogers PD. Genomewide expression profile analysis of the Candida glabrata Pdr1 regulon. Eukaryot Cell 2011; 10: 373-83.

102 Miyazaki H, Miyazaki Y, Geber A et al. Fluconazole resistance associated with drug efflux and increased transcription of a drug transporter gene, PDH1, in Candida glabrata. Antimicrob Agents Chemother 1998; 42: 1695-701.

103 Barchiesi F, Calabrese D, Sanglard D et al. Experimental induction of fluconazole resistance in Candida tropicalis ATCC 750. Antimicrob Agents Chemother 2000; 44: 1578-84.

104 Vandeputte P, Larcher G, Berges T, Renier G, Chabasse D, Bouchara JP. Mechanisms of azole resistance in a clinical isolate of Candida tropicalis. Antimicrob Agents Chemother 2005; 49: 4608-15.

105 Jiang C, Dong D, Yu B et al. Mechanisms of azole resistance in 52 clinical isolates of Candida tropicalis in China. J Antimicrob Chemother 2013; 68: 778-85.

106 Silva AP, Miranda IM, Guida A et al. Transcriptional profiling of azole-resistant Candida parapsilosis strains. Antimicrob Agents Chemother 2011; 55: 3546-56.

107 Sellam A, Tebbji F, Nantel A. Role of Ndt80p in sterol metabolism regulation and azole resistance in Candida albicans. Eukaryot Cell 2009; 8: 1174-83.

108 Chen CG, Yang YL, Shih HI, Su CL, Lo HJ. CaNdt80 is involved in drug resistance in Candida albicans by regulating CDR1. Antimicrob Agents Chemother 2004; 48: 4505-12.

109 Pao SS, Paulsen IT, Saier MH Jr. Major facilitator superfamily. Microbiol Mol Biol Rev 1998; 62: 1-34.

110 Morschhauser J, Barker KS, Liu TT, Bla BWJ, Homayouni R, Rogers PD. The transcription factor Mrrlp controls expression of the MDR1 efflux pump and mediates multidrug resistance in Candida albicans. PLoS Pathog 2007; 3: e164.

111 Dunkel N, Blass J, Rogers PD, Morschhauser J. Mutations in the multi-drug resistance regulator MRR1, followed by loss of heterozygosity, are the main cause of MDR1 overexpression in fluconazole-resistant Candida albicans strains. Mol Microbiol 2008; 69: $827-40$.

112 Schubert S, Rogers PD, Morschhauser J. Gain-of-function mutations in the transcription factor MRR1 are responsible for overexpression of the MDR1 efflux pump in fluconazole-resistant Candida dubliniensis strains. Antimicrob Agents Chemother 2008; 52: 4274-80.

113 Grossman NT, Pham CD, Cleveland AA, Lockhart SR. Molecular mechanisms of fluconazole resistance in Candida parapsilosis isolates from a U.S. surveillance system. Antimicrob Agents Chemother 2015; 59: $1030-7$.

114 Wirsching S, Michel S, Morschhauser J. Targeted gene disruption in Candida albicans wild-type strains: the role of the MDR1 gene in fluconazole resistance of clinical Candida albicans isolates. Mol Microbiol 2000; 36: 856-65.

115 Wirsching S, Moran GP, Sullivan DJ, Coleman DC, Morschhauser J. MDR1-mediated drug resistance in Candida dubliniensis. Antimicrob Agents Chemother 2001; 45: 3416-21.

116 Fuentes M, Hermosilla G, Alburquenque C, Falconer MA, Amaro J, Tapia C. [Characterization of azole resistance mechanisms in Chilean clinical isolates of Candida albicans]. Rev Chilena Infectol 2014; 31: $511-7$.

117 Moran G, Sullivan D, Morschhauser J, Coleman D. The Candida dubliniensis CdCDR1 gene is not essential for fluconazole resistance. Antimicrob Agents Chemother 2002; 46: 2829-41.

118 Rajendran R, Mowat E, McCulloch E et al. Azole resistance of Aspergillus fumigatus biofilms is partly associated with efflux pump activity. Antimicrob Agents Chemother 2011; 55: 2092-7.

119 Ferreira ME, Colombo AL, Paulsen I et al. The ergosterol biosynthesis pathway, transporter genes, and azole resistance in Aspergillus fumigatus. Med Mycol 2005; 43(Suppl 1): S313-9.

120 Slaven JW, Anderson MJ, Sanglard D et al. Increased expression of a novel Aspergillus fumigatus $\mathrm{ABC}$ transporter gene, atrF, in the presence of itraconazole in an itraconazole resistant clinical isolate. Fungal Genet Biol 2002; 36: 199-206.

121 da Silva Ferreira ME, Malavazi I, Savoldi M et al. Transcriptome analysis of Aspergillus fumigatus exposed to voriconazole. Curr Genet 2006; 50: 32-44.

122 Fraczek MG, Bromley M, Buied A et al. The cdr1B efflux transporter is associated with non-cyp51a-mediated itraconazole resistance in Aspergillus fumigatus. J Antimicrob Chemother 2013; 68: 1486-96. 
123 Monk BC, Tomasiak TM, Keniya MV et al. Architecture of a single membrane spanning cytochrome $\mathrm{P} 450$ suggests constraints that orient the catalytic domain relative to a bilayer. Proc Natl Acad Sci USA 2014; 111: 3865-70.

124 Snelders E, Karawajczyk A, Verhoeven RJ et al. The structure-function relationship of the Aspergillus fumigatus cyp51A L98H conversion by site-directed mutagenesis: the mechanism of L98H azole resistance. Fungal Genet Biol 2011; 48: 1062-70.

125 Morio F, Loge C, Besse B, Hennequin C, Le Pape P. Screening for amino acid substitutions in the Candida albicans Erg11 protein of azole-susceptible and azole-resistant clinical isolates: new substitutions and a review of the literature. Diagn Microbiol Infect Dis 2010; 66: $373-84$.

126 Chau AS, Mendrick CA, Sabatelli FJ, Loebenberg D, McNicholas PM. Application of real-time quantitative PCR to molecular analysis of Candida albicans strains exhibiting reduced susceptibility to azoles. Antimicrob Agents Chemother 2004; 48: 2124-31.

127 Kakeya H, Miyazaki Y, Miyazaki H, Nyswaner K, Grimberg B, Bennett JE. Genetic analysis of azole resistance in the Darlington strain of Candida albicans. Antimicrob Agents Chemother 2000; 44: 298590.

128 Lamb DC, Kelly DE, White TC, Kelly SL. The R467K amino acid substitution in Candida albicans sterol 14alpha-demethylase causes drug resistance through reduced affinity. Antimicrob Agents Chemother 2000; 44: 63-7.

129 Loffler J, Kelly SL, Hebart H, Schumacher U, Lass-Florl C, Einsele H. Molecular analysis of cyp51 from fluconazole-resistant Candida albicans strains. FEMS Microbiol Lett 1997; 151: 263-8.

130 Sanglard D, Ischer F, Koymans L, Bille J. Amino acid substitutions in the cytochrome P-450 lanosterol 14alpha-demethylase (CYP51A1) from azole-resistant Candida albicans clinical isolates contribute to resistance to azole antifungal agents. Antimicrob Agents Chemother 1998; 42: 241-53.

131 Perea S, Lopez-Ribot JL, Wickes BL et al. Molecular mechanisms of fluconazole resistance in Candida dubliniensis isolates from human immunodeficiency virus-infected patients with oropharyngeal candidiasis. Antimicrob Agents Chemother 2002; 46: 1695-703.

132 Forastiero A, Mesa-Arango AC, Alastruey-Izquierdo A et al. Candida tropicalis antifungal cross-resistance is related to different azole target (Erg11p) modifications. Antimicrob Agents Chemother 2013; 57: 4769-81.

133 Ricardo E, Miranda IM, Faria-Ramos I, Silva RM, Rodrigues AG, Pina-Vaz C. In vivo and in vitro acquisition of resistance to voriconazole by Candida krusei. Antimicrob Agents Chemother 2014; 58: $4604-11$.

134 Couzigou C, Gabriel F, Biteau N, Fitton-Ouhabi V, Noel T, Accoceberry I. Two missense mutations, E123Q and K151E, identified in the ERG11 allele of an azole-resistant isolate of Candida kefyr recovered from a stem cell transplant patient for acute myeloid leukemia. Med Mycol Case Rep 2014; 5: 12-5.

135 Hull CM, Parker JE, Bader O et al. Facultative sterol uptake in an ergosterol-deficient clinical isolate of Candida glabrata harboring a missense mutation in ERG11 and exhibiting cross-resistance to azoles and amphotericin B. Antimicrob Agents Chemother 2012; 56 4223-32.

136 Mellado E, Garcia-Effron G, Buitrago MJ, Alcazar-Fuoli L, CuencaEstrella M, Rodriguez-Tudela JL. Targeted gene disruption of the 14-alpha sterol demethylase (cyp51A) in Aspergillus fumigatus and its role in azole drug susceptibility. Antimicrob Agents Chemother 2005; 49: 2536-8.

$137 \mathrm{Hu} \mathrm{W}$, Sillaots S, Lemieux S et al. Essential gene identification and drug target prioritization in Aspergillus fumigatus. PLoS Pathog 2007; 3: e24.

138 Rodriguez-Tudela JL, Alcazar-Fuoli L, Cuesta I et al. Clinical relevance of resistance to antifungals. Int J Antimicrob Agents 2008; 32 (Suppl 2): S111-3.

139 Mellado E, Garcia-Effron G, Alcazar-Fuoli L, Cuenca-Estrella M, Rodriguez-Tudela JL. Substitutions at methionine 220 in the 14alpha-sterol demethylase (Cyp51A) of Aspergillus fumigatus are responsible for resistance in vitro to azole antifungal drugs. Antimicrob Agents Chemother 2004; 48: 2747-50.

140 Denning DW, Park S, Lass-Florl C et al. High-frequency triazole resistance found In nonculturable Aspergillus fumigatus from lungs of patients with chronic fungal disease. Clin Infect Dis 2011; 52: 1123-9.

141 Bader O, Weig M, Reichard U et al. cyp51A-Based mechanisms of Aspergillus fumigatus azole drug resistance present in clinical samples from Germany. Antimicrob Agents Chemother 2013; 57: 3513-7.

142 Becher R, Wirsel SG. Fungal cytochrome P450 sterol 14alphademethylase (CYP51) and azole resistance in plant and human pathogens. Appl Microbiol Biotechnol 2012; 95: 825-40.

143 Alcazar-Fuoli L, Mellado E. Current status of antifungal resistance and its impact on clinical practice. Br J Haematol 2014; 166: 471-84.

144 Vermeulen E, Lagrou K, Verweij PE. Azole resistance in Aspergillus fumigatus: a growing public health concern. Curr Opin Infect Dis 2013; 26: 493-500.

145 Paul S, Moye-Rowley WS. Multidrug resistance in fungi: regulation of transporter-encoding gene expression. Front Physiol 2014; 5: 143 .

146 Kidd SE, Goeman E, Meis JF, Slavin MA, Verweij PE. Multi-triazoleresistant Aspergillus fumigatus infections in Australia. Mycoses 2015; 58: $350-5$.

147 Wu CJ, Wang HC, Lee JC et al. Azole-resistant Aspergillus fumigatus isolates carrying $\mathrm{TR}_{34} / \mathrm{L} 98 \mathrm{H}$ mutations in Taiwan. Mycoses 2015; 58: 544-9.

148 Asano M, Kano R, Makimura K, Hasegawa A, Kamata H. Molecular typing and in-vitro activity of azoles against clinical isolates of Aspergillus fumigatus and A. niger in Japan. J Infect Chemother 2011; 17: 483-6.

149 Hagiwara D, Takahashi H, Watanabe A et al. Whole-genome comparison of Aspergillus fumigatus strains serially isolated from patients with aspergillosis. J Clin Microbiol 2014; 52: 4202-9.

150 Abdolrasouli A, Rhodes J, Beale MA et al. Genomic context of azole resistance mutations in Aspergillus fumigatus determined using whole-genome sequencing. MBio 2015; 6: e00536. doi:10.1128/ mBio. 00536-15.

151 Astvad KM, Jensen RH, Hassan TM et al. First detection of TR46/ Y121F/T289A and TR34/L98H alterations in Aspergillus fumigatus isolates from azole-naive patients in Denmark despite negative findings in the environment. Antimicrob Agents Chemother 2014; 58 : 5096-101.

152 Chowdhary A, Sharma C, Kathuria S, Hagen F, Meis JF. Azole-resistant Aspergillus fumigatus with the environmental TR46/Y121F/ T289A mutation in India. J Antimicrob Chemother 2014; 69 : 555-7.

153 Chowdhary A, Sharma C, Hagen F, Meis JF. Exploring azole antifungal drug resistance in Aspergillus fumigatus with special reference to resistance mechanisms. Future Microbiol 2014; 9 : $697-711$.

154 Chen Y, Wang H, Lu Z et al. Emergence of TR46/Y121F/T289A in an Aspergillus fumigatus isolate from a Chinese patient. Antimicrob Agents Chemother 2015; 59: 7148-50.

155 Pelaez T, Monteiro MC, Garcia-Rubio R, Bouza E, Gomez-Lopez A, Mellado E. First detection of Aspergillus fumigatus azole-resistant strain due to Cyp51A TR46/Y121F/T289A in an azole-naive patient in Spain. New Microbes New Infect 2015; 6: 33-4.

156 Lavergne RA, Morio F, Favennec L et al. First description of azoleresistant Aspergillus fumigatus due to TR46/Y121F/T289A mutation in France. Antimicrob Agents Chemother 2015; 59: 4331-5.

157 Steinmann J, Hamprecht A, Vehreschild MJ et al. Emergence of azole-resistant invasive aspergillosis in HSCT recipients in Germany. J Antimicrob Chemother 2015; 70: 1522-6.

158 Le Pape P, Lavergne RA, Morio F, Alvarez C. Multiple fungicide-driven alterations in azole-resistant Aspergillus fumigatus, Colombia, 2015. Emerg Infect Dis 2016; 22: 156-7. in press. http://dx.doi. org/10.3201/eid2201.1510978. 
159 Hodiamont CJ, Dolman KM, Ten Berge IJ, Melchers WJ, Verweij PE, Pajkrt D. Multiple-azole-resistant Aspergillus fumigatus osteomyelitis in a patient with chronic granulomatous disease successfully treated with long-term oral posaconazole and surgery. Med Mycol 2009; 47: 217-20.

160 Morschhauser J. The genetic basis of fluconazole resistance development in Candida albicans. Biochim Biophys Acta 2002; 1587: 240-8.

161 Redding SW, Kirkpatrick WR, Coco BJ et al. Candida glabrata oropharyngeal candidiasis in patients receiving radiation treatment for head and neck cancer. J Clin Microbiol 2002; 40: 1879-81.

162 Rogers PD, Vermitsky JP, Edlind TD, Hilliard GM. Proteomic analysis of experimentally induced azole resistance in Candida glabrata. J Antimicrob Chemother 2006; 58: 434-8.

163 Tavakoli M, Zaini F, Kordbacheh M, Safara M, Raoofian R, Heidari M. Upregulation of the ERG11 gene in Candida krusei by azoles. Daru 2010; 18: 276-80.

164 Blatzer M, Barker BM, Willger SD et al. SREBP coordinates iron and ergosterol homeostasis to mediate triazole drug and hypoxia responses in the human fungal pathogen Aspergillus fumigatus. PLoS Genet 2011; 7: e1002374.

165 Moye-Rowley WS. Multiple mechanisms contribute to the development of clinically significant azole resistance in Aspergillus fumigatus. Front Microbiol 2015; 6: 70.

166 Willger SD, Puttikamonkul S, Kim KH et al. A sterol-regulatory element binding protein is required for cell polarity, hypoxia adaptation, azole drug resistance, and virulence in Aspergillus fumigatus. PLoS Pathog 2008; 4: e1000200.

167 Camps SM, van der Linden JW, Li Y et al. Rapid induction of multiple resistance mechanisms in Aspergillus fumigatus during azole therapy: a case study and review of the literature. Antimicrob Agents Chemother 2012; 56: 10-6.

168 Tuncher A, Sprote P, Gehrke A, Brakhage AA. The CCAAT-binding complex of eukaryotes: evolution of a second NLS in the HapB subunit of the filamentous fungus Aspergillus nidulans despite functional conservation at the molecular level between yeast, A.nidulans and human. J Mol Biol 2005; 352: 517-33.

169 Ben-Ami R, Olshtain-Pops K, Krieger M et al. Antibiotic exposure as a risk factor for fluconazole-resistant Candida bloodstream infection. Antimicrob Agents Chemother 2012; 56: 2518-23.

170 Mikulska M, Del Bono V, Ratto S, Viscoli C. Occurrence, presentation and treatment of candidemia. Expert Rev Clin Immunol 2012; 8: $755-65$.

171 Lortholary O, Renaudat C, Sitbon K et al. Worrisome trends in incidence and mortality of candidemia in intensive care units (Paris area, 2002-2010). Intensive Care Med 2014; 40: 1303-12.

172 Schuster MG, Meibohm A, Lloyd L, Strom B. Risk factors and outcomes of Candida krusei bloodstream infection: a matched, case-control study. I Infect 2013; 66: 278-84.

173 Garnacho-Montero J, Diaz-Martin A, Garcia-Cabrera E et al. Risk factors for fluconazole-resistant candidemia. Antimicrob Agents Chemother 2010; 54: 3149-54.

174 Cuervo G, Puig-Asensio M, Garcia-Vidal C et al. A simple prediction score for estimating the risk of candidaemia caused by fluconazole non-susceptible strains. Clin Microbiol Infect 2015; 21: e1-9.

175 Denning DW, Radford SA, Oakley KL, Hall L, Johnson EM, Warnock DW. Correlation between in-vitro susceptibility testing to itraconazole and in-vivo outcome of Aspergillus fumigatus infection. J Antimicrob Chemother 1997; 40: 401-14.

176 Moore CB, Sayers N, Mosquera J, Slaven J, Denning DW. Antifungal drug resistance in Aspergillus. J Infect 2000; 41: 203-20.

177 Mortensen KL, Jensen RH, Johansen HK et al. Aspergillus species and other molds in respiratory samples from patients with cystic fibrosis: a laboratory-based study with focus on Aspergillus fumigatus azole resistance. J Clin Microbiol 2011; 49: 2243-51.

178 Howard SJ, Pasqualotto AC, Anderson MJ et al. Major variations in Aspergillus fumigatus arising within aspergillomas in chronic pulmonary aspergillosis. Mycoses 2013; 56: 434-41.
179 Snelders E, Melchers WJ, Verweij PE. Azole resistance in Aspergillus fumigatus: a new challenge in the management of invasive aspergillosis? Future Microbiol 2011; 6: 335-47.

180 Badali H, Vaezi A, Haghani I et al. Environmental study of azoleresistant Aspergillus fumigatus with TR34/L98H mutations in the cyp51A gene in Iran. Mycoses 2013; 56: 659-63.

181 Camps SM, Rijs AJ, Klaassen CH et al. Molecular epidemiology of Aspergillus fumigatus isolates harboring the TR34/L98H azole resistance mechanism. J Clin Microbiol 2012; 50: 2674-80.

182 Hamprecht A, Buchheidt D, Vehreschild JJ et al. Azole-resistant invasive aspergillosis in a patient with acute myeloid leukaemia in Germany. Euro Surveill 2012; 17: 20262.

183 Burgel PR, Baixench MT, Amsellem M et al. High prevalence of azole-resistant Aspergillus fumigatus in adults with cystic fibrosis exposed to itraconazole. Antimicrob Agents Chemother 2012; 56: $869-74$.

184 Stensvold RC, Jørgensen LN, Arendrup MC. Azole-resistant invasive aspergillosis: relationship to agriculture. Curr Fung Infect Rep 2012; 6: 178-91.

185 Deresinski SC, Stevens DA. Caspofungin. Clin Infect Dis 2003; 36: $1445-57$.

186 Morris MI, Villmann M. Echinocandins in the management of invasive fungal infections, Part 2. Am J Health Syst Pharm 2006; 63: 1813-20.

187 Chandrasekar PH, Sobel JD. Micafungin: a new echinocandin. Clin Infect Dis 2006; 42: 1171-8.

188 Pappas PG, Kauffman CA, Andes D et al. Clinical practice guidelines for the management of candidiasis: 2009 update by the Infectious Diseases Society of America. Clin Infect Dis 2009; 48: 503-35.

189 Viscoli C, Herbrecht R, Akan H et al. An EORTC Phase II study of caspofungin as first-line therapy of invasive aspergillosis in haematological patients. J Antimicrob Chemother 2009; 64: 1274-81.

190 Colombo AL, Guimaraes T, Camargo LF et al. Brazilian guidelines for the management of candidiasis - a joint meeting report of three medical societies: Sociedade Brasileira de Infectologia, Sociedade Paulista de Infectologia and Sociedade Brasileira de Medicina Tropical. Braz J Infect Dis 2013; 17: 283-312.

191 Fekkar A, Dannaoui E, Meyer I et al. Emergence of echinocandinresistant Candida spp. in a hospital setting: a consequence of 10 years of increasing use of antifungal therapy? Eur J Clin Microbiol Infect Dis 2014; 33: 1489-96.

192 Cleveland AA, Harrison LH, Farley MM et al. Declining incidence of candidemia and the shifting epidemiology of Candida resistance in two US metropolitan areas, 2008-2013: results from populationbased surveillance. PLoS ONE 2015; 10: e0120452.

193 Maubon D, Garnaud C, Calandra T, Sanglard D, Cornet M. Resistance of Candida spp. to antifungal drugs in the ICU: where are we now? Intensive Care Med 2014; 40: 1241-55.

194 Alexander BD, Johnson MD, Pfeiffer CD et al. Increasing echinocandin resistance in Candida glabrata: clinical failure correlates with presence of FKS mutations and elevated minimum inhibitory concentrations. Clin Infect Dis 2013; 56: 1724-32.

195 Arendrup MC, Perlin DS. Echinocandin resistance: an emerging clinical problem? Curr Opin Infect Dis 2014; 27: 484-92.

196 Bizerra FC, Jimenez-Ortigosa C, Souza AC et al. Breakthrough candidemia due to multidrug-resistant Candida glabrata during prophylaxis with a low dose of micafungin. Antimicrob Agents Chemother 2014; 58: 2438-40.

197 Arendrup MC. Invasive fungal infections: past achievements and challenges ahead. Clin Microbiol Infect 2009; 15: 599-601.

198 Marr KA, Schlamm HT, Herbrecht R et al. Combination antifungal therapy for invasive aspergillosis: a randomized trial. Ann Intern Med 2015; 162: 81-9.

199 Walsh TJ, Anaissie EJ, Denning DW et al. Treatment of aspergillosis: clinical practice guidelines of the Infectious Diseases Society of America. Clin Infect Dis 2008; 46: 327-60.

200 Staab JF, Kahn JN, Marr KA. Differential Aspergillus lentulus echinocandin susceptibilities are Fksp independent. Antimicrob Agents Chemother 2010; 54: 4992-8. 
201 Eschertzhuber S, Velik-Salchner C, Hoermann C, Hoefer D, LassFlorl C. Caspofungin-resistant Aspergillus flavus after heart transplantation and mechanical circulatory support: a case report. Transpl Infect Dis 2008; 10: 190-2.

202 Barchiesi F, Spreghini E, Tomassetti S et al. Effects of caspofungin against Candida guilliermondii and Candida parapsilosis. Antimicrob Agents Chemother 2006; 50: 2719-27.

203 Kahn JN, Hsu MJ, Racine F, Giacobbe R, Motyl M. Caspofungin susceptibility in Aspergillus and non-Aspergillus molds: inhibition of glucan synthase and reduction of beta-D-1,3 glucan levels in culture. Antimicrob Agents Chemother 2006; 50: 2214-6.

204 Enache-Angoulvant A, Girard A, Poirot JL, Hennequin C. In vitro activity of caspofungin and voriconazole against uncommon Candida spp. Int J Antimicrob Agents 2009; 33: 595-6.

205 Mazur P, Morin N, Baginsky W et al. Differential expression and function of two homologous subunits of yeast 1,3-beta-D-glucan synthase. Mol Cell Biol 1995; 15: 5671-81.

206 Ishihara S, Hirata A, Nogami S, Beauvais A, Latge JP, Ohya Y. Homologous subunits of 1,3-beta-glucan synthase are important for spore wall assembly in Saccharomyces cerevisiae. Eukaryot Cell 2007; 6: $143-56$.

207 Katiyar SK, Alastruey-Izquierdo A, Healey KR, Johnson ME, Perlin DS, Edlind TD. Fks1 and Fks2 are functionally redundant but differentially regulated in Candida glabrata: implications for echinocandin resistance. Antimicrob Agents Chemother 2012; 56: 6304-9.

208 Perlin DS. Current perspectives on echinocandin class drugs. Future Microbiol 2011; 6: 441-57.

209 Balashov SV, Park S, Perlin DS. Assessing resistance to the echinocandin antifungal drug caspofungin in Candida albicans by profiling mutations in FKS1. Antimicrob Agents Chemother 2006; 50: $2058-63$.

210 Garcia-Effron G, Chua DJ, Tomada JR et al. Novel FKS mutations associated with echinocandin resistance in Candida species. Antimicrob Agents Chemother 2010; 54: 2225-7.

211 Perlin DS. Resistance to echinocandin-class antifungal drugs. Drug Resist Updat 2007; 10: 121-30.

212 Walker LA, Gow NA, Munro CA. Fungal echinocandin resistance. Fungal Genet Biol 2010; 47: 117-26.

213 Park S, Kelly R, Kahn JN et al. Specific substitutions in the echinocandin target Fks1p account for reduced susceptibility of rare laboratory and clinical Candida sp. isolates. Antimicrob Agents Chemother 2005; 49: 3264-73.

214 Desnos-Ollivier M, Bretagne S, Raoux D et al. Mutations in the fks1 gene in Candida albicans, C. tropicalis, and C. krusei correlate with elevated caspofungin MICs uncovered in AM3 medium using the method of the European Committee on Antibiotic Susceptibility Testing. Antimicrob Agents Chemother 2008; 52: 3092-8.

215 Dannaoui E, Desnos-Ollivier M, Garcia-Hermoso D et al. Candida spp. with acquired echinocandin resistance, France, 2004-2010. Emerg Infect Dis 2012; 18: 86-90.

216 Garcia-Effron G, Katiyar SK, Park S, Edlind TD, Perlin DS. A naturally occurring proline-to-alanine amino acid change in Fkslp in Candida parapsilosis, Candida orthopsilosis, and Candida metapsilosis accounts for reduced echinocandin susceptibility. Antimicrob Agents Chemother 2008; 52: 2305-12.

217 Jensen RH, Johansen HK, Arendrup MC. Stepwise development of a homozygous S80P substitution in Fks1p, conferring echinocandin resistance in Candida tropicalis. Antimicrob Agents Chemother 2013; 57: 614-7.

218 Pham CD, Iqbal N, Bolden CB et al. Role of FKS Mutations in Candida glabrata: MIC values, echinocandin resistance, and multidrug resistance. Antimicrob Agents Chemother 2014; 58: 4690-6.

219 Cleary JD, Garcia-Effron G, Chapman SW, Perlin DS. Reduced Candida glabrata susceptibility secondary to an FKS1 mutation developed during candidemia treatment. Antimicrob Agents Chemother 2008; 52: 2263-5.

220 Thompson GR 3rd, Wiederhold NP, Vallor AC, Villareal NC, Lewis JS, Patterson TF. Development of caspofungin resistance following prolonged therapy for invasive candidiasis secondary to Candida glabrata infection. Antimicrob Agents Chemother 2008; 52: 3783-5.

221 Katiyar S, Pfaller M, Edlind T. Candida albicans and Candida glabrata clinical isolates exhibiting reduced echinocandin susceptibility. Antimicrob Agents Chemother 2006; 50: 2892-4.

222 Pfaller MA, Boyken L, Hollis RJ et al. In vitro susceptibility of invasive isolates of Candida spp. to anidulafungin, caspofungin, and micafungin: six years of global surveillance. J Clin Microbiol 2008; 46: 150-6.

223 Pfaller MA, Boyken L, Hollis RJ et al. Wild-type MIC distributions and epidemiological cutoff values for the echinocandins and Candida spp. J Clin Microbiol 2010; 48: 52-6.

224 Tortorano AM, Prigitano A, Lazzarini C et al. A 1-year prospective survey of candidemia in Italy and changing epidemiology over one decade. Infection 2013; 41: 655-62.

225 Colombo AL, Ngai AL, Bourque $\mathrm{M}$ et al. Caspofungin use in patients with invasive candidiasis caused by common non-albicans Candida species: review of the caspofungin database. Antimicrob Agents Chemother 2010; 54: 1864-71.

226 Foldi R, Kovacs R, Gesztelyi R et al. Comparison of in vitro and vivo efficacy of caspofungin against Candida parapsilosis, C. orthopsilosis, C. metapsilosis and C. albicans. Mycopathologia 2012; 174: 311-8.

227 Spreghini E, Orlando F, Tavanti A et al. In vitro and in vivo effects of echinocandins against Candida parapsilosis sensu stricto, Candida orthopsilosis and Candida metapsilosis. J Antimicrob Chemother 2012; 67: 2195-202.

228 Szilagyi J, Foldi R, Gesztelyi R et al. Comparison of the kidney fungal burden in experimental disseminated candidiasis by species of the Candida parapsilosis complex treated with fluconazole, amphotericin B and caspofungin in a temporarily neutropenic murine model. Chemotherapy 2012; 58: 159-64.

229 Fernandez-Ruiz M, Aguado JM, Almirante B et al. Initial use of echinocandins does not negatively influence outcome in Candida parapsilosis bloodstream infection: a propensity score analysis. Clin Infect Dis 2014; 58: 1413-21.

230 Arendrup MC, Perkhofer S, Howard SJ et al. Establishing in vitroin vivo correlations for Aspergillus fumigatus: the challenge of azoles versus echinocandins. Antimicrob Agents Chemother 2008; 52: 3504-11.

231 Arendrup MC, Garcia-Effron G, Buzina W et al. Breakthrough Aspergillus fumigatus and Candida albicans double infection during caspofungin treatment: laboratory characteristics and implication for susceptibility testing. Antimicrob Agents Chemother 2009; 53: 1185-93.

232 Gardiner RE, Souteropoulos P, Park S, Perlin DS. Characterization of Aspergillus fumigatus mutants with reduced susceptibility to caspofungin. Med Mycol 2005; 43(Suppl 1): S299-305.

233 Rocha EM, Garcia-Effron G, Park S, Perlin DS. A Ser678Pro substitution in Fkslp confers resistance to echinocandin drugs in Aspergillus fumigatus. Antimicrob Agents Chemother 2007; 51: 4174-6.

234 Imhof A, Balajee SA, Marr KA. New methods to assess susceptibilities of Aspergillus isolates to caspofungin. J Clin Microbiol 2003; 41: 5683-8.

235 Walker LA, Munro CA, de Bruijn I, Lenardon MD, McKinnon A, Gow NA. Stimulation of chitin synthesis rescues Candida albicans from echinocandins. PLoS Pathog 2008; 4: e1000040.

236 Plaine A, Walker L, Da Costa G et al. Functional analysis of Candida albicans GPI-anchored proteins: roles in cell wall integrity and caspofungin sensitivity. Fungal Genet Biol 2008; 45: 1404-14.

237 Walker LA, Gow NA, Munro CA. Elevated chitin content reduces the susceptibility of Candida species to caspofungin. Antimicrob Agents Chemother 2013; 57: 146-54.

238 Cota JM, Grabinski JL, Talbert RL et al. Increases in SLT2 expression and chitin content are associated with incomplete killing of Candida glabrata by caspofungin. Antimicrob Agents Chemother 2008; 52: 1144-6.

239 Blanchard E, Lortholary O, Boukris-Sitbon K et al. Prior caspofungin exposure in patients with hematological malignancies is a risk factor for subsequent fungemia due to decreased susceptibility in 
Candida spp.: a case-control study in Paris, France. Antimicrob Agents Chemother 2011; 55: 5358-61.

240 Lortholary O, Desnos-Ollivier M, Sitbon K et al. Recent exposure to caspofungin or fluconazole influences the epidemiology of candidemia: a prospective multicenter study involving 2,441 patients. Antimicrob Agents Chemother 2011; 55: 532-8.

241 Shields RK, Nguyen MH, Press EG et al. The presence of an FKS mutation rather than MIC is an independent risk factor for failure of echinocandin therapy among patients with invasive candidiasis due to Candida glabrata. Antimicrob Agents Chemother 2012; 56: 4862-9.

242 Beyda ND, John J, Kilic A, Alam MJ, Lasco TM, Garey KW. FKS mutant Candida glabrata: risk factors and outcomes in patients with candidemia. Clin Infect Dis 2014; 59: 819-25.

243 Farmakiotis D, Tarrand JJ, Kontoyiannis DP. Drug-resistant Candida glabrata infection in cancer patients. Emerg Infect Dis 2014; 20: 1833-40.

244 Ruggero MA, Topal JE. Development of echinocandin-resistant Candida albicans candidemia following brief prophylactic exposure to micafungin therapy. Transpl Infect Dis 2014; 16: 469-72.

245 Perfect JR, Dismukes WE, Dromer F et al. Clinical practice guidelines for the management of cryptococcal disease: 2010 update by the infectious diseases society of america. Clin Infect Dis 2010; 50: 291-322.

246 Wheat LJ, Freifeld AG, Kleiman MB et al. Clinical practice guidelines for the management of patients with histoplasmosis: 2007 update by the Infectious Diseases Society of America. Clin Infect Dis 2007; 45: $807-25$.

247 Kuse ER, Chetchotisakd P, da Cunha CA et al. Micafungin versus liposomal amphotericin B for candidaemia and invasive candidosis: a phase III randomised double-blind trial. Lancet 2007; 369: $1519-27$.

248 Odds FC, Brown AJ, Gow NA. Antifungal agents: mechanisms of action. Trends Microbiol 2003; 11: 272-9.

249 Masia Canuto M, Gutierrez Rodero F. Antifungal drug resistance to azoles and polyenes. Lancet Infect Dis 2002; 2: 550-63.

250 Mesa-Arango AC, Trevijano-Contador N, Roman E et al. The production of reactive oxygen species is a universal action mechanism of amphotericin B against pathogenic yeasts and contributes to the fungicidal effect of this drug. Antimicrob Agents Chemother 2014; 58: $6627-38$.

251 Peman J, Canton E, Espinel-Ingroff A. Antifungal drug resistance mechanisms. Expert Rev Anti Infect Ther 2009; 7: 453-60.

252 Mohr JF, Hall AC, Ericsson CD, Ostrosky-Zeichner L. Fatal amphotericin B overdose due to administration of nonlipid formulation instead of lipid formulation. Pharmacotherapy 2005; 25: 426-8.

253 Wang YH, Zhang JP, Chang Y, Hu CQ. A newly identified derivative of amphotericin B: isolation, structure determination and primary evaluation of the activity and toxicity. J Antibiot (Tokyo) 2010; 63: 553-7

254 Bates DW, Su L, Yu DT et al. Mortality and costs of acute renal failure associated with amphotericin B therapy. Clin Infect Dis 2001; 32: 686-93.

255 Falci DR, da Rosa FB, Pasqualotto AC. Comparison of nephrotoxicity associated to different lipid formulations of amphotericin B: a real-life study. Mycoses 2015; 58: 104-12.

256 Falci DR, da Rosa FB, Pasqualotto AC. Hematological toxicities associated with amphotericin B formulations. Leuk Lymphoma 2015; 56: 2889-94

257 Groll AH, Muller FM, Piscitelli SC, Walsh TJ. Lipid formulations of amphotericin B: clinical perspectives for the management of invasive fungal infections in children with cancer. Klin Padiatr 1998; 210: $264-73$.

258 Bowden R. Chandrasekar P, White MH et al. A double-blind, randomized, controlled trial of amphotericin B colloidal dispersion versus amphotericin B for treatment of invasive aspergillosis in immunocompromised patients. Clin Infect Dis 2002; 35 : 359-66.
259 Walsh TJ, Hiemenz JW, Seibel NL et al. Amphotericin B lipid complex for invasive fungal infections: analysis of safety and efficacy in 556 cases. Clin Infect Dis 1998; 26: 1383-96.

260 Bowden RA, Cays M, Gooley T, Mamelok RD, van Burik JA. Phase I study of amphotericin B colloidal dispersion for the treatment of invasive fungal infections after marrow transplant. J Infect Dis 1996; 173: 1208-15.

261 Wingard JR. Lipid formulations of amphotericins: are you a lumper or a splitter? Clin Infect Dis 2002; 35: 891-5.

262 da Matta DA, de Almeida LP, Machado AM et al. Antifungal susceptibility of 1000 Candida bloodstream isolates to 5 antifungal drugs: results of a multicenter study conducted in Sao Paulo, Brazil, 1995-2003. Diagn Microbiol Infect Dis 2007; 57: 399-404.

263 Pfaller MA, Diekema DJ. Epidemiology of invasive candidiasis: a persistent public health problem. Clin Microbiol Rev 2007; 20: 133-63.

264 Nolte FS, Parkinson T, Falconer DJ et al. Isolation and characterization of fluconazole- and amphotericin B-resistant Candida albicans from blood of two patients with leukemia. Antimicrob Agents Chemother 1997; 41: 196-9.

265 Clancy CJ, Nguyen MH. Correlation between in vitro susceptibility determined by $\mathrm{E}$ test and response to therapy with amphotericin B: results from a multicenter prospective study of candidemia. Antimicrob Agents Chemother 1999; 43: 1289-90.

266 Krogh-Madsen M, Arendrup MC, Heslet L, Knudsen JD. Amphotericin B and caspofungin resistance in Candida glabrata isolates recovered from a critically ill patient. Clin Infect Dis 2006; 42: 938-44.

267 Favel A, Michel-Nguyen A, Peyron F et al. Colony morphology switching of Candida lusitaniae and acquisition of multidrug resistance during treatment of a renal infection in a newborn: case report and review of the literature. Diagn Microbiol Infect Dis 2003; 47: 331-9

268 Pfaller MA, Boyken L, Messer SA, Tendolkar S, Hollis RJ, Diekema DJ. Evaluation of the etest method using Mueller-Hinton agar with glucose and methylene blue for determining amphotericin B MICs for 4,936 clinical isolates of Candida species. J Clin Microbiol 2004 42: 4977-9.

269 Zaoutis TE, Foraker E, McGowan KL et al. Antifungal susceptibility of Candida spp. isolated from pediatric patients: a survey of 4 children's hospitals. Diagn Microbiol Infect Dis 2005; 52: 295-8.

270 Chen SC, Marriott D, Playford EG et al. Candidaemia with uncommon Candida species: predisposing factors, outcome, antifungal susceptibility, and implications for management. Clin Microbiol Infect 2009; 15: 662-9.

271 Pfaller MA, Diekema DJ, Gibbs DL et al. Results from the ARTEMIS DISK Global sntifungal surveillance study, 1997 to 2007: a 10.5year analysis of susceptibilities of Candida species to fluconazole and voriconazole as determined by CLSI standardized disk diffusion. $J$ Clin Microbiol 2010; 48: 1366-77.

272 Atkinson BJ, Lewis RE, Kontoyiannis DP. Candida lusitaniae fungemia in cancer patients: risk factors for amphotericin B failure and outcome. Med Mycol 2008; 46: 541-6.

273 Merz WG. Candida lusitaniae: frequency of recovery, colonization, infection, and amphotericin B resistance. J Clin Microbiol 1984; 20: 1194-5.

274 Minari A, Hachem R, Raad I. Candida lusitaniae: a cause of breakthrough fungemia in cancer patients. Clin Infect Dis 2001; 32 186-90.

275 Moosa MY, Alangaden GJ, Manavathu E, Chandrasekar PH. Resistance to amphotericin B does not emerge during treatment for invasive aspergillosis. J Antimicrob Chemother 2002; 49: 209-13.

276 Steinbach WJ, Benjamin DK, Kontoyiannis DP et al. Infections due to Aspergillus terreus: a multicenter retrospective analysis of 83 cases. Clin Infect Dis 2004; 39: 192-8.

277 Hadrich I, Makni F, Neji S et al. Amphotericin B in vitro resistance is associated with fatal Aspergillus flavus infection. Med Mycol 2012; 50: $829-34$. 
278 Guinea J, Pelaez T, Alcala L, Ruiz-Serrano MJ, Bouza E. Antifungal susceptibility of 596 Aspergillus fumigatus strains isolated from outdoor air, hospital air, and clinical samples: analysis by site of isolation. Antimicrob Agents Chemother 2005; 49: 3495-7.

279 Diekema DJ, Messer SA, Hollis RJ, Jones RN, Pfaller MA. Activities of caspofungin, itraconazole, posaconazole, ravuconazole, voriconazole, and amphotericin B against 448 recent clinical isolates of filamentous fungi. J Clin Microbiol 2003; 41: 3623-6.

280 Lass-Florl C, Griff K, Mayr A et al. Epidemiology and outcome of infections due to Aspergillus terreus: 10-year single centre experience. Br J Haematol 2005; 131: 201-7.

281 Lass-Florl C, Kofler G, Kropshofer G et al. In-vitro testing of susceptibility to amphotericin B is a reliable predictor of clinical outcome in invasive aspergillosis. J Antimicrob Chemother 1998; 42: 497502.

282 Sanglard D, Ischer F, Parkinson T, Falconer D, Bille J. Candida albicans mutations in the ergosterol biosynthetic pathway and resistance to several antifungal agents. Antimicrob Agents Chemother 2003; 47: 2404-12.

283 Young LY, Hull CM, Heitman J. Disruption of ergosterol biosynthesis confers resistance to amphotericin B in Candida lusitaniae. Antimicrob Agents Chemother 2003; 47: 2717-24.

284 Vandeputte P, Tronchin G, Berges T, Hennequin C, Chabasse D, Bouchara JP. Reduced susceptibility to polyenes associated with a missense mutation in the ERG6 gene in a clinical isolate of Candida glabrata with pseudohyphal growth. Antimicrob Agents Chemother 2007; 51: 982-90.

285 Vandeputte P, Tronchin G, Larcher G et al. A nonsense mutation in the ERG6 gene leads to reduced susceptibility to polyenes in a clinical isolate of Candida glabrata. Antimicrob Agents Chemother 2008; 52: 3701-9.

286 Martel CM, Parker JE, Bader O et al. A clinical isolate of Candida albicans with mutations in ERG11 (encoding sterol 14alphademethylase) and ERG5 (encoding C22 desaturase) is cross resistant to azoles and amphotericin B. Antimicrob Agents Chemother 2010; 54: $3578-83$.

287 Chamilos G, Kontoyiannis DP. Update on antifungal drug resistance mechanisms of Aspergillus fumigatus. Drug Resist Updat 2005; 8: 344-58.

288 Blum G, Perkhofer S, Grif K et al. A 1-year Aspergillus terreus surveillance study at the University Hospital of Innsbruck: molecular typing of environmental and clinical isolates. Clin Microbiol Infect 2008; 14: 1146-51.

289 Blatzer M, Jukic E, Posch W et al. Amphotericin B resistance in Aspergillus terreus is overpowered by coapplication of pro-oxidants. Antioxid Redox Signal 2015; 23: 1424-38.

290 Nucci M, Queiroz-Telles F, Alvarado-Matute T et al. Epidemiology of candidemia in Latin America: a laboratory-based survey. PLOS ONE 2013; 8: e59373.

291 Cordoba S, Vivot W, Bosco-Borgeat ME et al. Species distribution and susceptibility profile of yeasts isolated from blood cultures: results of a multicenter active laboratory-based surveillance study in Argentina. Rev Argent Microbiol 2011; 43: 176-85.

292 Silva V, Diaz MC, Febre N. Chilean Invasive Fungal Infections G. Invasive fungal infections in Chile: a multicenter study of fungal prevalence and susceptibility during a 1-year period. Med Mycol 2004; 42: 333-9.

293 Dolande Franco ME, Reviakina V, Panizo MM et al. Distribution and antifungal susceptibility of Candida clinical isolations coming from six health care centers in the metropolitan area of Caracas, Venezuela (years 2003-2005). Rev Iberoam Micol 2008; 25: 17-21.

294 Cortes JA, Reyes P, Gomez CH et al. Clinical and epidemiological characteristics and risk factors for mortality in patients with candidemia in hospitals from Bogota. Colombia. Braz J Infect Dis 2014; 18: $631-7$.

295 Corzo-Leon DE, Alvarado-Matute T, Colombo AL et al. Surveillance of Candida spp bloodstream infections: epidemiological trends and risk factors of death in two Mexican tertiary care hospitals. PLoS ONE 2014; 9: e97325.
296 Aquino VR, Lunardi LW, Goldani LZ, Barth AL. Prevalence, susceptibility profile for fluconazole and risk factors for candidemia in a tertiary care hospital in southern Brazil. Braz J Infect Dis 2005; 9: 411-8.

297 Colombo AL, Nucci M, Park BJ et al. Epidemiology of candidemia in Brazil: a nationwide sentinel surveillance of candidemia in eleven medical centers. J Clin Microbiol 2006; 44: 2816-23.

298 Bruder-Nascimento A, Camargo CH, Sugizaki MF et al. Species distribution and susceptibility profile of Candida species in a Brazilian public tertiary hospital. BMC Res Notes 2010; 3: 1.

299 Santos ER, Dal Forno CF, Hernandez MG et al. Susceptibility of Candida spp. isolated from blood cultures as evaluated using the M27A3 and new M27-S4 approved breakpoints. Rev Inst Med Trop Sao Paulo 2014; 56: 477-82.

300 da Costa VG, Quesada RM, Abe AT, Furlaneto-Maia L, Furlaneto MC. Nosocomial bloodstream Candida infections in a tertiary-care hospital in South Brazil: a 4-year survey. Mycopathologia 2014; 178: $243-50$.

301 Hong SB, Shin HD, Hong J et al. New taxa of Neosartorya and Aspergillus in Aspergillus section Fumigati. Antonie Van Leeuwenhoek 2008; 93: 87-98.

302 Balajee SA, Kano R, Baddley JW et al. Molecular identification of Aspergillus species collected for the Transplant-Associated Infection Surveillance Network. J Clin Microbiol 2009; 47: 3138-41.

303 Montenegro G, Sanchez Puch S, Jewtuchowicz VM et al. Phenotypic and genotypic characterization of Aspergillus lentulus and Aspergillus fumigatus isolates in a patient with probable invasive aspergillosis. J Med Microbiol 2009; 58: 391-5.

304 Alhambra A, Catalan M, Moragues MD et al. Isolation of Aspergillus lentulus in Spain from a critically ill patient with chronic obstructive pulmonary disease. Rev Iberoam Micol 2008; 25: 246-9.

305 Vinh DC, Shea YR, Sugui JA et al. Invasive aspergillosis due to Neosartorya udagawae. Clin Infect Dis 2009; 49: 102-11.

306 Sugui JA, Vinh DC, Nardone G et al. Neosartorya udagawae (Aspergillus udagawae), an emerging agent of aspergillosis: how different is it from Aspergillus fumigatus? J Clin Microbiol 2010; 48: 220-8.

307 Balajee SA, Marr KA. Phenotypic and genotypic identification of human pathogenic aspergilli. Future Microbiol 2006; 1: 435-45.

308 Vinh DC, Shea YR, Jones PA, Freeman AF, Zelazny A, Holland SM. Chronic invasive aspergillosis caused by Aspergillus viridinutans. Emerg Infect Dis 2009; 15: 1292-4.

309 Krishnan S, Manavathu EK, Chandrasekar PH. Aspergillus flavus: an emerging non-fumigatus Aspergillus species of significance. Mycoses 2009; 52: 206-22.

310 Gomez-Lopez A, Garcia-Effron G, Mellado E, Monzon A, RodriguezTudela JL, Cuenca-Estrella M. In vitro activities of three licensed antifungal agents against spanish clinical isolates of Aspergillus spp. Antimicrob Agents Chemother 2003; 47: 3085-8.

311 Hsueh PR, Lau YJ, Chuang YC et al. Antifungal susceptibilities of clinical isolates of Candida species, Cryptococcus neoformans, and Aspergillus species from Taiwan: surveillance of multicenter antimicrobial resistance in Taiwan program data from 2003. Antimicrob Agents Chemother 2005; 49: 512-7.

312 Lionakis MS, Lewis RE, Torres HA, Albert ND, Raad II, Kontoyiannis DP. Increased frequency of non-fumigatus Aspergillus species in amphotericin B- or triazole-pre-exposed cancer patients with positive cultures for aspergilli. Diagn Microbiol Infect Dis 2005; 52: 15-20.

313 Koss T, Bagheri B, Zeana C, Romagnoli MF, Grossman ME. Amphotericin B-resistant Aspergillus flavus infection successfully treated with caspofungin, a novel antifungal agent. J Am Acad Dermatol 2002; 46: 945-7.

314 Johnson EM, Oakley KL, Radford SA et al. Lack of correlation of in vitro amphotericin B susceptibility testing with outcome in a murine model of Aspergillus infection. J Antimicrob Chemother 2000; 45: 85-93.

315 Segal BH, DeCarlo ES, Kwon-Chung KJ, Malech HL, Gallin JI, Holland SM. Aspergillus nidulans infection in chronic granulomatous disease. Medicine (Baltimore) 1998; 77: 345-54. 
316 Kontoyiannis DP, Lewis RE, May GS, Osherov N, Rinaldi MG. Aspergillus nidulans is frequently resistant to amphotericin B. Mycoses 2002; 45: 406-7.

317 Verweij PE, Varga J, Houbraken J et al. Emericella quadrilineata as cause of invasive aspergillosis. Emerg Infect Dis 2008; 14: 566-72.

318 Lass-Florl C, Alastruey-Izquierdo A, Cuenca-Estrella M, Perkhofer S, Rodriguez-Tudela JL. In vitro activities of various antifungal drugs against Aspergillus terreus: Global assessment using the methodology of the European committee on antimicrobial susceptibility testing. Antimicrob Agents Chemother 2009; 53: 794-5.

319 Sutton DA, Sanche SE, Revankar SG, Fothergill AW, Rinaldi MG. In vitro amphotericin B resistance in clinical isolates of Aspergillus terreus, with a head-to-head comparison to voriconazole. J Clin Microbiol 1999; 37: 2343-5.

320 Caston JJ, Linares MJ, Gallego C et al. Risk factors for pulmonary Aspergillus terreus infection in patients with positive culture for filamentous fungi. Chest 2007; 131: 230-6.

321 Hachem RY, Kontoyiannis DP, Boktour MR et al. Aspergillus terreus: an emerging amphotericin B-resistant opportunistic mold in patients with hematologic malignancies. Cancer 2004; 101: 1594-600.

322 Balajee SA, Baddley JW, Peterson SW et al. Aspergillus alabamensis, a new clinically relevant species in the section Terrei. Eukaryot Cell 2009; 8: 713-22.

323 Kaya AD, Kiraz N. In vitro susceptibilities of Aspergillus spp. causing otomycosis to amphotericin B, voriconazole and itraconazole. Mycoses 2007; 50: 447-50.
324 Alcazar-Fuoli L, Mellado E, Alastruey-Izquierdo A, Cuenca-Estrella M, Rodriguez-Tudela JL. Species identification and antifungal susceptibility patterns of species belonging to Aspergillus section Nigri. Antimicrob Agents Chemother 2009; 53: 4514-7.

325 Morgan J, Wannemuehler KA, Marr KA et al. Incidence of invasive aspergillosis following hematopoietic stem cell and solid organ transplantation: interim results of a prospective multicenter surveillance program. Med Mycol 2005; 43(Suppl 1): S4958.

326 Varga J, Houbraken J, Van Der Lee HA, Verweij PE, Samson RA. Aspergillus calidoustus sp. nov., causative agent of human infections previously assigned to Aspergillus ustus. Eukaryot Cell 2008; 7: 630-8.

327 Houbraken J, Due M, Varga J, Meijer M, Frisvad JC, Samson RA. Polyphasic taxonomy of Aspergillus section Usti. Stud Mycol 2007; 59: $107-28$.

328 Takahata Y, Hiruma M, Sugita T, Muto M. A case of onychomycosis due to Aspergillus sydowii diagnosed using DNA sequence analysis. Mycoses 2008; 51: 170-3.

329 Escribano P, Pelaez T, Munoz P, Bouza E, Guinea J. Is azole resistance in Aspergillus fumigatus a problem in Spain? Antimicrob Agents Chemother 2013; 57: 2815-20.

330 Alanio A, Sitterle E, Liance M et al. Low prevalence of resistance to azoles in Aspergillus fumigatus in a French cohort of patients treated for haematological malignancies. J Antimicrob Chemother 2011; 66: $371-4$ 